\title{
2,3-Dihydroquinazolin-4(1H)-one as a privileged scaffold in drug design
}

Cite this: RSC Adv., 2018, 8, 20894

\author{
Mariateresa Badolato, (D) ab Francesca Aiello (iD) ${ }^{a}$ and Nouri Neamati (iD) ${ }^{b}$
}

2,3-Dihydroquinazolin-4-one (DHQ) belongs to the class of nitrogen-containing heterocyclic compounds representing a core structural component in various biologically active compounds. In the past decades, several methodologies have been developed for the synthesis of the DHQ framework, especially the 2substituted derivatives. Unfortunately, multistep syntheses, harsh reaction conditions, and the use of toxic reagents and solvents have limited their full potential as a versatile fragment. Recently, use of green chemistry and alternative strategies are being explored to prepare diverse DHQ derivatives. This fragment is used as a synthon for the preparation of biologically active quinazolinones and as a functional substrate for the synthesis of modified DHQ derivatives exhibiting different biological properties. In this review, we provide a comprehensive assessment of the synthesis and biological evaluations of $\mathrm{DHQ}$ derivatives.

Received 2nd April 2018

Accepted 29th May 2018

DOI: $10.1039 / \mathrm{c} 8 \mathrm{ra02827c}$

rsc.li/rsc-advances nitrogen-containing motif consisting of a phenyl ring condensed with a six-membered ring with two nitrogen atoms on positions 1 and 3, and a keto group on carbon 4 (Fig. 1). Most of the DHQ derivatives are substituted on the carbon 2 chiral center. Due to their attractive properties, 2-substituted DHQs are becoming a prominent synthetic intermediate for organic chemists and various methodologies are reported in the literature for their preparation as racemic mixtures. Although some asymmetric strategies have been attempted, the aminal chiral center is sensitive to racemization, making it difficult to
Mariateresa Badolato is currently pursuing her PhD degree in Translational Medicine under the supervision of Dr Francesca Aiello and Professor Antonio Garofalo at the University of Calabria, Italy. She received her Master's degree in Pharmaceutical Technology and Chemistry at the University of Calabria in 2013. She worked for one year as a visiting scholar in Professor Neamati's laboratory at the Department of Medicinal Chemistry, College of Pharmacy, University of Michigan. With the project "RYGoldZip" guided by Dr Francesca Aiello, as a member of the team she won the Clinic Center Life Sciences award. Among various projects, she designed and synthesized several ligands for TRPV1 receptors. Her PhD dissertation focuses on the preclinical and mechanistic studies of small-molecule drugs targeting STAT3 and other signaling pathways for the treatment of various cancers.
Dr Francesca Aiello is an Assistant Professor of Medicinal Chemistry at the Department of Pharmacy, Health and Nutritional Sciences, University of Calabria, Italy. She obtained her PhD degree in Pharmaceutical and Technologies Chemistry from the University of Siena in 1998. In 1999, she obtained her qualification as a Pharmacist. She completed a Postdoctoral Research Fellowship under the supervision of Professor Neamati at the Department of Pharmacology and Pharmaceutical Sciences, School of Pharmacy, University of Southern California, Los Angeles, CA. She was a lecturer in Qualitative Analytical Medicinal Chemistry at the University of Calabria. During the past decade she received numerous grants from the University of Salerno, University of Calabria, and University of Siena to develop new anticancer chemotherapeutics, HIV-1 integrase inhibitors, and to synthesize new D3-receptor ligands. Dr Aiello has published 38 peer-reviewed manuscripts, 4 book chapters, and is an inventor in two patents in the area of Medicinal Chemistry. As leader of the project "RYGoldZip", she discovered and formulated a topical product with wound healing properties for diabetic ulcers and she won the Clinic Center Life Sciences award. 


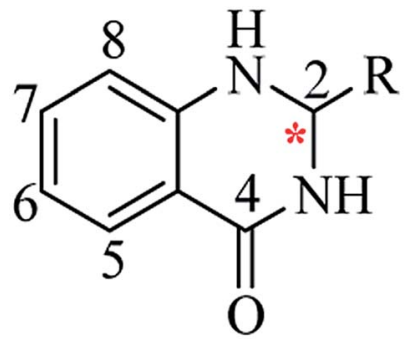

Fig. 1 2,3-Dihydroquinazolin-4(1H)-one framework.

synthesize pure enantiomers. ${ }^{3}$ The aim of the present review is to discuss reported methods for the synthesis of DHQ derivatives, highlighting their evolution towards alternative approaches and enantioselective strategies, and to summarize their use as synthons in organic chemistry and their important biological activities.

\section{2,3-Dihydroquinazolin-4(1H)-one: a privileged scaffold}

In 1988, Evans et al. introduced for the first time the concept of "privileged structures". They are useful tools in the field of drug discovery since they represent suitable lead compounds for diverse receptors and the rational optimization of such structures could provide new receptor modulators and potential drugs. ${ }^{4}$ Medicinal chemists exploit the "privileged structures" to synthesize new libraries of compounds based on a central scaffold and screen them against various receptors implicated in different pathways, in some cases yielding biologically active compounds. In this regard, the DHQ core is emerging as

Dr Nouri Neamati is the John G. Searle Professor of Medicinal Chemistry at the College of Pharmacy, University of Michigan and a member of the UM Translational Oncology Program. He obtained his PhD degree in Biomedical Sciences from the University of Texas Graduate School of Biomedical Sciences and MD Anderson Cancer Center, Houston, Texas in 1995. From 1995 to 2000, he was a postdoctoral and a research fellow at the National Institutes of Health (NIH) in Bethesda, MD. In September 2000, he joined the faculty at the School of Pharmacy, University of Southern California, with a joint appointment at the Norris Comprehensive Cancer Center. Professor Neamati is the recipient of numerous awards, including the NIH Technology Transfer, STOP CANCER, GlaxoSmithKline Drug Discovery Award, several Awards from the US Department of Defense, LUNGevity Discovery Award from the American Lung Association, and the Littlefield-AACR award in Metastatic Colon Cancer Research. He has published over 230 peerreviewed manuscripts, 20 book chapters, and is an inventor in over 30 patents in the area of drug design and discovery. He was the founding Editor-in-Chief of Current Molecular Pharmacology, and is currently an Associate Editor of the Journal of Medicinal Chemistry as well as Current Anticancer Drug Targets. He has served as an Editorial Advisory Board member of several journals, including Expert Opinion on Drug Discovery, Expert Opinion on Investigational Drugs, and Hormones \& Cancer. a "privileged scaffold" and a variety of its derivatives, having diverse mechanism of action, are currently used for the treatment of various diseases. ${ }^{5-11}$ A panel of marketed drugs with the DHQ core is shown in Fig. 2. Besides these marketed drugs, a number of new DHQ derivatives have been designed that exhibit a wide range of pharmacological properties. Because of their importance, the synthesis of substituted DHQ derivatives has attracted much attention and different synthetic strategies have been developed. Since the classical protocols involved the use of toxic reagents and solvents in harsh reaction conditions, the evolution towards simple, clean, environmentally benign and high-yielding methods is gaining momentum (Fig. 3).

\section{Conventional procedure: cyclocondensation of anthranilamide and an aldehyde}

Although numerous strategies have been developed for the construction of the DHQ core, the most common and simple synthetic route for the preparation of DHQs is the direct cyclocondensation of anthranilamide and an aldehyde (Scheme 1). In the past decades, different catalysts and organic solvents have been used to speed up and improve the general yield of the reaction (Table 1). Regardless of the used catalyst and/or solvent, the most presumed mechanism of cyclocondensation is shown in Scheme $2 .{ }^{12}$ The first step involves the nucleophilic attack of the nitrogen of the amino group of the anthranilamide on the carbonyl carbon of the aldehyde, promoted by the catalyst, resulting in the formation of hydroxyl intermediate I. Next, the catalyst promotes the formation of the Schiff base (II) from I through the removal of a water molecule. Finally, the imine undergoes intramolecular cyclization by nucleophilic attack of the nitrogen of the amide group on the imine carbon, to furnish the corresponding DHQ derivative.

A variation of the traditional cyclocondensation of anthranilamide and an aldehyde is represented by the intramolecular cyclization of a Schiff base. As shown in Scheme 3, the nucleophilic attack of the nitrogen of the amide group on the imine carbon leads to the cyclic DHQ derivative.

\section{Basic catalysis}

The base-catalyzed cyclocondensation of anthranilamide and an aldehyde was the first proposed strategy for the synthesis of DHQ derivatives. In 1967, Yale et al. prepared a new class of DHQs in the presence of $20 \%$ aqueous $\mathrm{NaOH}$ in refluxing EtOH. These compounds were tested for their inhibition of cell proliferation. ${ }^{13}$ Later, Bonola et al. used $\mathrm{NaOH}$ or NaOEt in absolute EtOH to prepare DHQs with antibacterial and antifungal activities. ${ }^{14}$ Ericsson et al. patented DHQ derivatives as anti-fertility agents; these compounds were prepared from anthranilamide and 1naphthaldehyde in the presence of $\mathrm{NaOH}$ in refluxing absolute EtOH..$^{15}$ The NaOH-catalyzed reactions gave moderate to high yields (60-85\%) in $1 \mathrm{~h}$ compared to NaOEt, which took $3-4 \mathrm{~h}$ to complete the formation of DHQs (Table 1). Depending on the available aldehyde, the use of a strong base as catalyst was not always successful. Because of this limitation, different catalysts were commonly used for the synthesis of DHQs starting from anthranilamide and an aldehyde. 
<smiles>CCC1NC(=O)c2cc(S(N)(=O)=O)c(Cl)cc2N1</smiles>

Quinethazone (antihypertensive, diuretic)<smiles>NS(=O)(=O)c1cc2c(cc1Cl)NC(c1ccccc1)NC2=O</smiles>

Fenquizone (diuretic)<smiles>Cc1ccccc1N1C(=O)c2cc(S(N)(=O)=O)c(Cl)cc2NC1C</smiles>

Metolazone (antihypertensive, diuretic)<smiles>Cc1ccc(N2C(=O)c3ccccc3NC2C(C)c2ccccc2)cc1</smiles>

VU0092145 (neurotransmitter)<smiles>CN1c2ccccc2C(=O)N2CCc3c([nH]c4ccccc34)C21</smiles>

Evodiamine (thermogenic, stimulant)<smiles>Cc1ccccc1-n1c(CF)nc2ccc(N)cc2c1=O</smiles>

Afloqualone (sedative, muscle-relaxant)<smiles>Cc1ccccc1-n1c(C)nc2ccccc2c1=O</smiles>

Methaqualone (sedative, hypnotic)<smiles>Cc1ccc2[nH]c(N)nc(=O)c2c1Sc1ccncc1</smiles>

Nolatrexed (antineoplastic)<smiles>Cc1ccc2c(-c3ccccc3)nc(=O)n(C(C)C)c2c1</smiles>

Proquazone (non-steroidal anti-inflammatory)<smiles>C[C@H](n1cnc2ccc(N)cc2c1=O)[C@@](O)(Cn1cncn1)c1cc(F)cc(F)c1</smiles>

Albaconazole (antifungal)

Fig. 2 The "privileged scaffold" DHQ in marketed drugs.

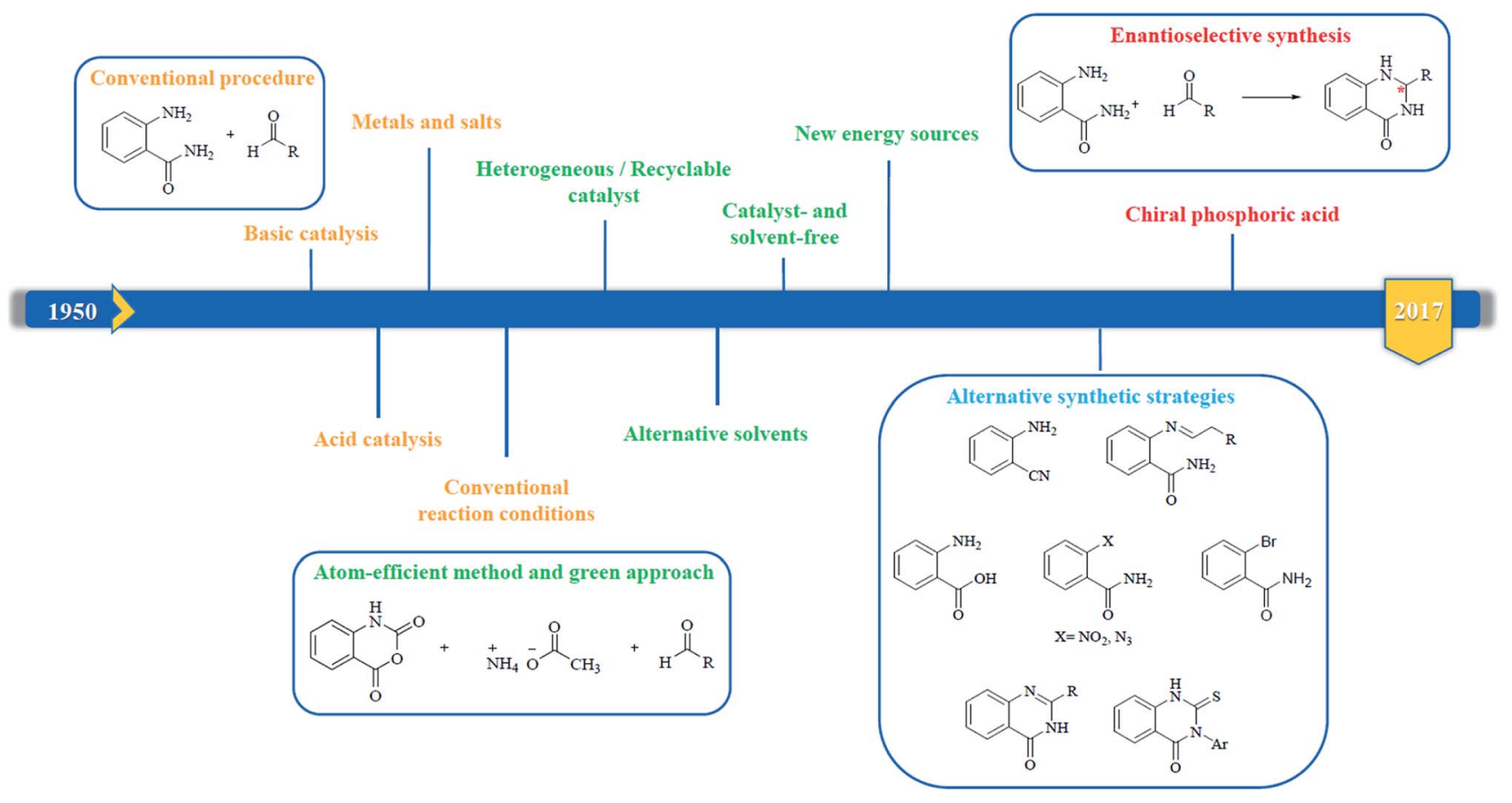

Fig. 3 Evolution of the synthetic strategies to prepare DHQ core. 


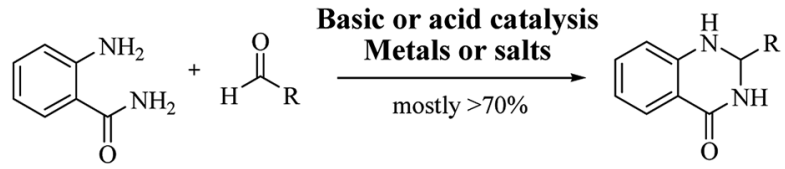

Scheme 1 Direct cyclocondensation of anthranilamide and aldehyde under conventional conditions.

\section{Acid catalysis}

As shown in Table 1, more frequently, the cyclocondensation of anthranilamide and an aldehyde is performed in acid catalysis. $\mathrm{HCl}$ in $\mathrm{EtOH}^{14}$ or in association with concentrated $\mathrm{HNO}_{3}$ (ref. 16) was used as catalyst under reflux conditions. As reported, DHQ derivatives were often synthesized in the presence of a catalytic amount of $\mathrm{H}_{2} \mathrm{SO}_{4}$ (ref. 17) or by using catalysts bearing sulfonic acid functionality. Among them, $p$-toluenesulfonic acid was used in different solvents, including boiling chlorobenzene, ${ }^{13}$ benzene, ${ }^{18} \quad N, N$-dimethylacetamide ${ }^{19,20}$ and EtOH. $^{21}$ 2-( $N$-Morpholino)ethanesulfonic acid, commonly used as a buffering agent in biology, also stood out as a mild acid catalyst for the cyclocondensation of anthranilamide and an aldehyde. ${ }^{22}$ The use of sulfanilic acid, ${ }^{23} \mathrm{NaHSO}_{4},{ }^{24,25}$ and $\mathrm{SOCl}_{2},{ }^{26}$ as a catalyst in EtOH has also been described. Moreover, formic acid ${ }^{\mathbf{1 2}}$ as catalyst and solvent, as well as malonic $\operatorname{acid}^{27}$ in aqueous EtOH (50\%), were used for the synthesis of DHQs. Furthermore, boric acid $\left(\mathrm{H}_{3} \mathrm{BO}_{3}\right),{ }^{28}$ and propylphosphonic anhydride, ${ }^{29}$ usually employed in the Fisher indole synthesis and the Pictet-Spengler reaction, efficiently catalyzed the cyclocondensation of anthranilamide and aldehydes.

\section{Iodine and metal salts as catalysts}

Molecular iodine $\left(\mathrm{I}_{2}\right)$ emerged as a versatile, inexpensive and non-toxic catalyst, which serves as a Lewis acid. It is suitable in the cyclocondensation of anthranilamide and aldehydes, in ionic liquids, ${ }^{30,31}$ or in EtOAc. ${ }^{32}$ A synthesis in aqueous medium was also attempted. Due to poor solubility of $\mathrm{I}_{2}$ in water, $1 \mathrm{~mol} \%$ of $\mathrm{I}_{2}$ as Lugol's solution ( $\left.\mathrm{I}_{2} / \mathrm{KI}\right)$ was used to prepare DHQs. ${ }^{33}$ In the presence of $\mathrm{I}_{2}$ as catalyst, DHQ derivatives were obtained with $66-95 \%$ yield, but the reactions required up to $15 \mathrm{~h}$ to complete.

Table 1 Conventional conditions for the cyclocondensation of anthranilamide and an aldehyde

\begin{tabular}{|c|c|c|c|c|c|}
\hline Nature catalyst & Catalyst & Conditions & Time & Yield & Ref. \\
\hline \multirow[t]{2}{*}{ Strong base } & $\mathrm{NaOH}$ & EtOH, reflux & $1 \mathrm{~h}$ & $60-86 \%$ & $13-15$ \\
\hline & NaOEt & EtOH, reflux & $3-4 \mathrm{~h}$ & $20-85 \%$ & 14 \\
\hline \multirow[t]{3}{*}{ Strong BrØnsted acid } & $\mathrm{HCl}$ & EtOH, reflux & $4 \mathrm{~h}$ & $10 \%$ & 14 \\
\hline & Conc. $\mathrm{HNO}_{3} / \mathrm{HCl}$ & Reflux $\rightarrow$ rt & $5 \rightarrow 30 \mathrm{~min}$ & $>98 \%$ & 16 \\
\hline & $\mathrm{H}_{2} \mathrm{SO}_{4}$ & Solvent-free, MWI & Few min & $68-78 \%$ & 17 \\
\hline \multirow[t]{9}{*}{ Sulfonic acid functionality } & PTSA & Chlorobenzene, reflux & $1 \mathrm{~h}$ & $74 \%$ & 13 \\
\hline & & Benzene, reflux & $4 \mathrm{~h}$ & $70 \%$ & 18 \\
\hline & & DMAC, rt/reflux & $1-2 \mathrm{~h}$ & $75-95 \%$ & 19 and 20 \\
\hline & & EtOH, reflux & $1 \mathrm{~h}$ & $70-90 \%$ & 21 \\
\hline & MES & Aq. EtOH (50\%), MWI & $5-20 \mathrm{~min}$ & $83-96 \%$ & 22 \\
\hline & Sulfanilic acid & Aq. EtOH $(50 \%), 70{ }^{\circ} \mathrm{C}$ & & & 23 \\
\hline & $\mathrm{NaHSO}_{4}$ & $\mathrm{EtOH}, \mathrm{rt}$ & $0.5-5.5 \mathrm{~h}$ & $91-97 \%$ & 24 \\
\hline & & $\mathrm{H}_{2} \mathrm{O}$, grinding $\mathrm{rt} \rightarrow 60{ }^{\circ} \mathrm{C}$ & $0.5-7 \mathrm{~h}$ & $54-97 \%$ & 25 \\
\hline & $\mathrm{SOCl}_{2}$ & EtOH, rt & $30-35 \mathrm{~min}$ & $93-95 \%$ & 26 \\
\hline \multirow[t]{2}{*}{ Weak BrØnsted acid } & Formic acid & $20^{\circ} \mathrm{C}$ & & & 12 \\
\hline & Malonic acid & Aq. EtOH (50\%), rt & 5-37 $\mathrm{min}$ & $81-98 \%$ & 27 \\
\hline Weak Lewis acid & $\mathrm{H}_{3} \mathrm{BO}_{3}$ & Solvent-free, $120{ }^{\circ} \mathrm{C}$ & $5 \mathrm{~min}$ & $82-90 \%$ & 28 \\
\hline Organic & $\mathrm{T} 3 \mathrm{P} ®$ & $\mathrm{AcCN}, \mathrm{rt}$ & $10-15 \mathrm{~min}$ & $85-94 \%$ & 29 \\
\hline \multirow[t]{2}{*}{ Lewis acid } & $\mathrm{I}_{2}$ & ILs, $50{ }^{\circ} \mathrm{C} / 80{ }^{\circ} \mathrm{C}$ & $0.5-10 \mathrm{~h}$ & $76-99 \%$ & 30 and 31 \\
\hline & & EtOAc, $h v$ & $1-15 \mathrm{~h}$ & $66-93 \%$ & 32 \\
\hline Lugol's solution & $\mathrm{I}_{2} / \mathrm{KI}$ & $\mathrm{H}_{2} \mathrm{O}, \mathrm{rt}$ & $2-12 \mathrm{~h}$ & $47-95 \%$ & 33 \\
\hline Organic & $\mathrm{C}_{3} \mathrm{Cl}_{3} \mathrm{~N}_{3}$ & $\mathrm{AcCN}, \mathrm{rt}$ & $8-20 \mathrm{~min}$ & $60-96 \%$ & 40 \\
\hline \multirow[t]{12}{*}{ Lewis acid } & $\mathrm{Mn}\left(\mathrm{CH}_{3} \mathrm{COO}\right)_{2}$ & EtOH, reflux & $5 \mathrm{~h}$ & & 34 \\
\hline & $\mathrm{ZrCl}_{2}$ & EtOH, rt & $9-60 \min$ & $80-97 \%$ & 35 \\
\hline & $\mathrm{HgCl}_{2}$ & $\mathrm{EtOH}, 60^{\circ} \mathrm{C}$ & $1-2 \mathrm{~h}$ & $88-94 \%$ & 36 \\
\hline & $\mathrm{Cp}_{2} \mathrm{TiCl}_{2}$ & EtOH, rt & $7-9 \min$ & $95-98 \%$ & 37 \\
\hline & $\mathrm{InBr}_{3}$ & $\mathrm{AcCN}, \mathrm{rt}$ & $10-60 \mathrm{~min}$ & $75-98 \%$ & 38 \\
\hline & $\mathrm{BiBr}_{3}$ & $\mathrm{AcCN}, \mathrm{rt}$ & $30 \mathrm{~min}$ & $80-95 \%$ & 39 \\
\hline & $\mathrm{Sc}(\mathrm{OTf})_{3}$ & EtOH, $70{ }^{\circ} \mathrm{C}$ & $20-40 \mathrm{~min}$ & $85-92 \%$ & 42 \\
\hline & & Dry DCM, rt & $4-7 \mathrm{~h}$ & $85-94 \%$ & 43 \\
\hline & & PEG-400, $80^{\circ} \mathrm{C}$ & $2 \mathrm{~h}$ & $78-90 \%$ & 44 \\
\hline & $\mathrm{Yb}(\mathrm{OTf})_{3}$ & $\mathrm{EtOH}, 80^{\circ} \mathrm{C}$ & $2-6 \mathrm{~h}$ & $>95 \%$ & 45 \\
\hline & & $\mathrm{IL}, \mathrm{rt}$ & $6-8 \mathrm{~h}$ & $85-96 \%$ & 46 \\
\hline & $\mathrm{Y}(\mathrm{OTf})_{3}$ & EtOH, rt & $1.5 \mathrm{~h}$ & $88-99 \%$ & 47 \\
\hline \multirow[t]{3}{*}{ Ammonium salt } & $\mathrm{NH}_{4} \mathrm{Cl}$ & EtOH, rt/reflux & 5-120 min & $78-98 \%$ & 48 and 49 \\
\hline & $\mathrm{CAN}$ & $\mathrm{H}_{2} \mathrm{O}, \mathrm{rt} \rightarrow 60^{\circ} \mathrm{C}$ & $1-8 \mathrm{~h}$ & $62-97 \%$ & 50 \\
\hline & TBAHS & MeOH, reflux & $2 \mathrm{~h}$ & $64-90 \%$ & 51 \\
\hline
\end{tabular}




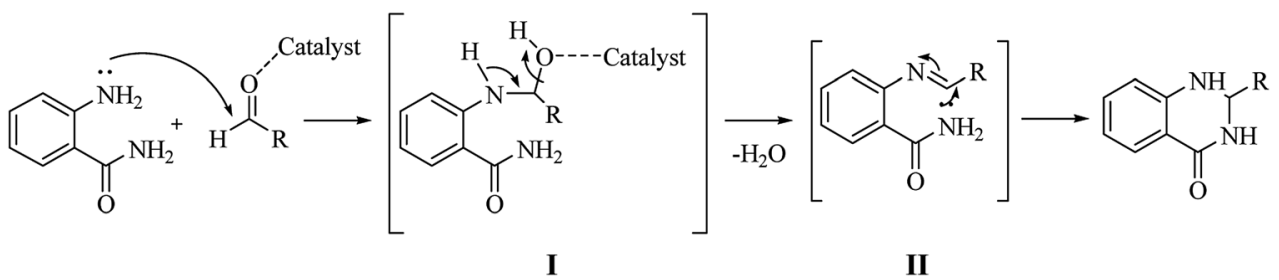

Scheme 2 Presumed mechanism of the cyclocondensation of anthranilamide and an aldehyde.

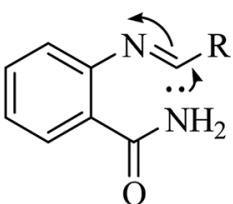
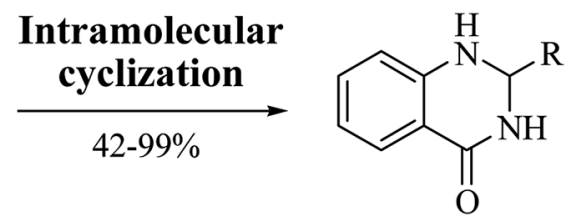

Scheme 3 Intramolecular cyclization of a Schiff base

Table 2 Reaction conditions for the intramolecular cyclization of a Schiff base

\begin{tabular}{lllll}
\hline Substrate & Conditions & Time & \% Yield & Ref. \\
\hline \multirow{2}{*}{ Schiff base } & $\mathrm{NaH}, \mathrm{THF}, 0{ }^{\circ} \mathrm{C} \rightarrow \mathrm{rt}$ & $16 \mathrm{~h}$ & $42-91$ & 52 \\
& $\mathrm{~N}_{2}, \mathrm{EtOH}$, reflux & $6 \mathrm{~h}$ & 83 & 53 \\
& $\mathrm{Fe}_{3} \mathrm{O}_{4} \mathrm{NPs}, \mathrm{EtOH}$, reflux & $1-3.5 \mathrm{~h}$ & $94-98$ & 54 \\
& $\mathrm{AcOH}$, reflux & $1.5 \mathrm{~h}$ & $80-92$ & 55 and 56
\end{tabular}

Transition metal salts are excellent catalysts due to their kinetic stability, low toxicity and intrinsic metallic Lewis acidity. They were used in various organic transformations, including the cyclocondensation of anthranilamide and aldehydes..$^{34,40}$ In particular, the use of transition metal salts reduced reaction time from hours to minutes without decreasing the yield. Compared to conventional Lewis acids, metal triflates are better catalysts in organic synthesis because of their chemical and physical properties, such as moisture and air-stability, recoverability, operational simplicity, and a strong tolerance to oxygen, nitrogen, phosphorus, and sulfur-containing reaction substrates and functional groups. ${ }^{41}$ Among them, scandium, ${ }^{42-44}$ ytterbium, ${ }^{45,46}$ and yttrium ${ }^{47}$ triflates were extensively used in various conditions to catalyze the cyclocondensation of anthranilamide and aldehydes, leading to DHQs with high yields (78-99\%) in 0.3-8 $\mathrm{h}$.

As shown in Table 1, even ammonium salts stood out as good catalysts for the preparation of DHQ derivatives. ${ }^{48-51}$ The reactions required short time and yields were up to $60 \%$.

\section{Intramolecular cyclization of a Schiff base}

The synthesis of DHQs through intramolecular cyclization of a Schiff base was performed under different conditions, providing DHQs with $42-99 \%$ yield in 1-16 h (Table 2). While strong basic conditions gave the final product in long time, ${ }^{52}$ the use of molecular nitrogen shortened the completion of the reaction. ${ }^{53} \mathrm{~A}$ rapid synthesis was obtained using metal oxide nanoparticles, ${ }^{54}$ and under catalyst-free conditions. ${ }^{55,56}$

\section{An atom-efficient method: one-pot three-component synthesis}

Although the cyclocondensation of anthranilamide and aldehydes is a facile and simple approach to obtain the DHQ core, more advantageous strategies to synthesize DHQ derivatives remain a desired goal in organic chemistry. The first evolution towards a more convenient approach was moving from a twocomponent reaction (anthranilamide and an aldehyde) to a one-pot three-component reaction (isatoic anhydride, ammonium acetate and an aldehyde) (Scheme 4). Initially, Staiger $e t$ al. suggested this strategy about half a century ago, ${ }^{57}$ and recently the advantages of multi-component reactions have been highlighted. Compared to conventional synthesis, the onepot three-component reaction represents an attractive and atom-efficient method to efficiently prepare the DHQ framework.

Multi-component reactions are characterized by (i) atom economy, incorporating all materials used in the process into the final product; (ii) high levels of diversity achieved simply by varying the reaction components; (iii) time-efficiency, since products are formed in a single step, allowing a fast probe of a chemical hypothesis; and (iv) simple experimental procedures, ideally there is no need to isolate the intermediates. Obviously, the adoption of such a strategy minimizes both waste production and cost..$^{58}$ The plausible mechanism of the one-pot three-component synthesis of DHQs is shown in Scheme 5. Initially, the catalyst facilitates the nucleophilic attack of $\mathrm{NH}_{4} \mathrm{OAc}$ on the carbonyl carbon of the isatoic anhydride. Nucleophilic addition of ammonium leads to<smiles>[R]C(=O)[CH+]C(=O)O[Na]</smiles>

Scheme 4 Preparation of DHQ through one-pot three-component reaction. 


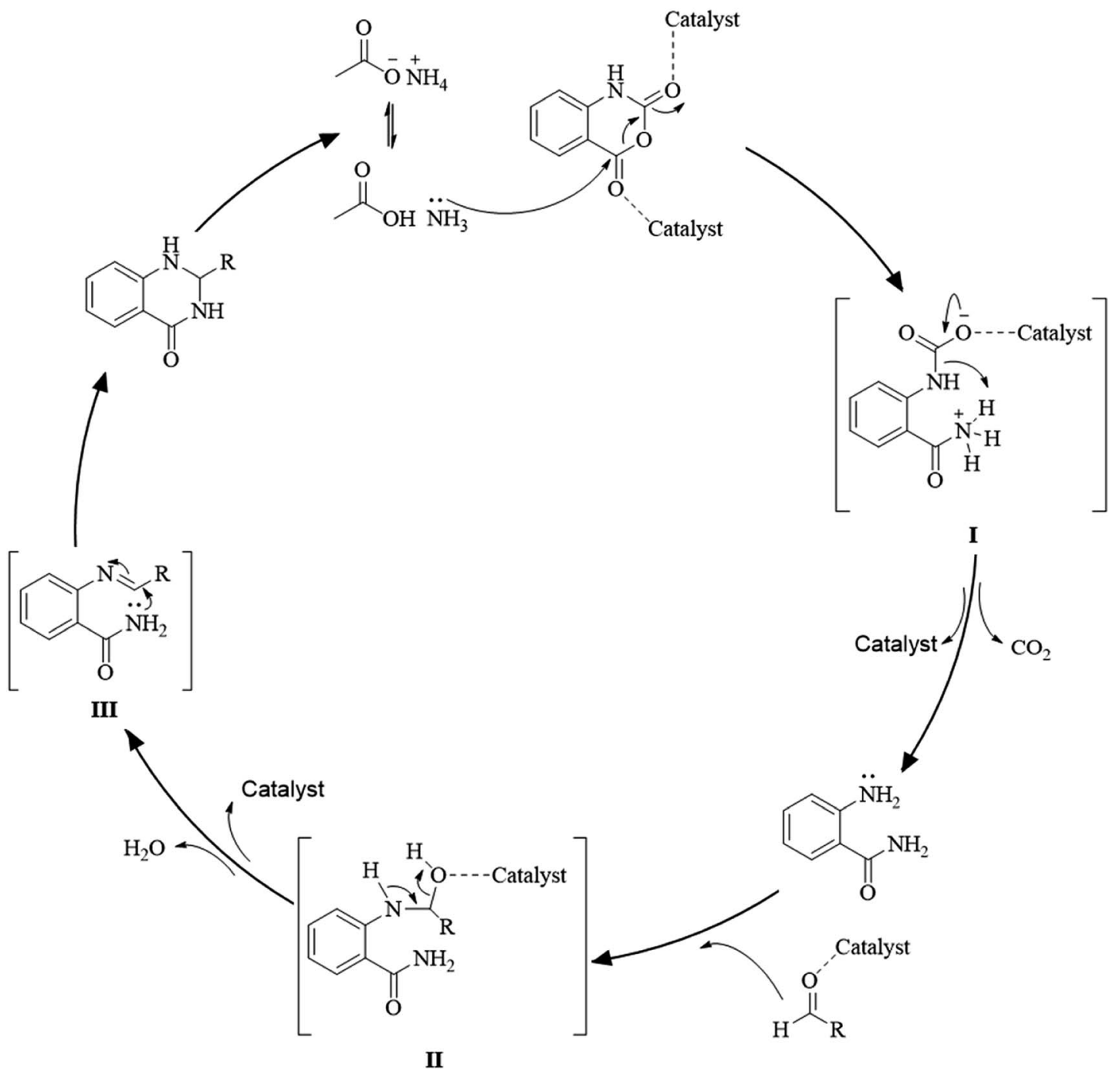

Scheme 5 Plausible mechanism of the one-pot three-component synthesis of DHQ.

intermediate I while the following decarboxylation produces anthranilamide (II). Then, the reaction proceeds similarly to the cyclocondensation. The catalyst promotes the nucleophilic attack of the amino group of II on the carbonyl carbon of the aldehyde, resulting in the formation of the Schiff base (III) by removing a water molecule. Finally, the imine intramolecularly cyclizes by nucleophilic attack of the nitrogen of the amide group on the imine carbon, to furnish the corresponding DHQ derivative. Examples of various catalysts and organic solvents used in the reaction of isatoic anhydride, $\mathrm{NH}_{4} \mathrm{OAc}$ and an aldehyde are listed in Table 3.

\section{Conventional reaction conditions}

In general, the one-pot three-component syntheses of DHQs were performed under acid-catalyzed conditions (Table 3). BrØnsted acid catalysts, such as ethylenediamine diacetate ${ }^{59}$ and pentafluorophenylammonium triflate $^{60}$ were used under reflux conditions, giving DHQ derivatives with $86-95 \%$ yield in about $10 \mathrm{~h}$ or less. Catalysts bearing sulfonic acid functionalities were also widely used in the multi-component reactions. ${ }^{61-66}$ They significantly reduced the reaction time, generating DHQs with 50-98\% yield. Recently, the use of $N$-halo sulfonamides as catalysts, broadly reported in organic synthesis, has been attempted in the one-pot three-component reaction. ${ }^{67}$ Metal-catalyzed multi-component synthesis of DHQ derivatives was also reported. ${ }^{68-73}$ Generally, the use of metals or Lewis acids as catalysts did not lead to great yields $(<90 \%)$, except when $\mathrm{I}_{2}$ is used under solvent-free conditions at $115{ }^{\circ} \mathrm{C}^{69}$ (Table 3).

\section{Recyclable catalysts}

To improve the one-pot three-component reaction using green chemistry, the use of recyclable catalysts was introduced to further minimize waste production (Table 3). Some Lewis acid catalysts had the advantage of being easily recovered after the reaction and recycled several times without considerable loss of reactivity. ${ }^{63,64,66,71}$

$\beta$-Cyclodextrin ( $\beta$-CD) is a cyclic oligosaccharide, composed of seven glucose units connected "head-to-tail" by 1,4-links. This cyclic heptamer has a truncated cone shape, with 
Table 3 Reaction conditions for the one-pot three-component synthesis of DHQs

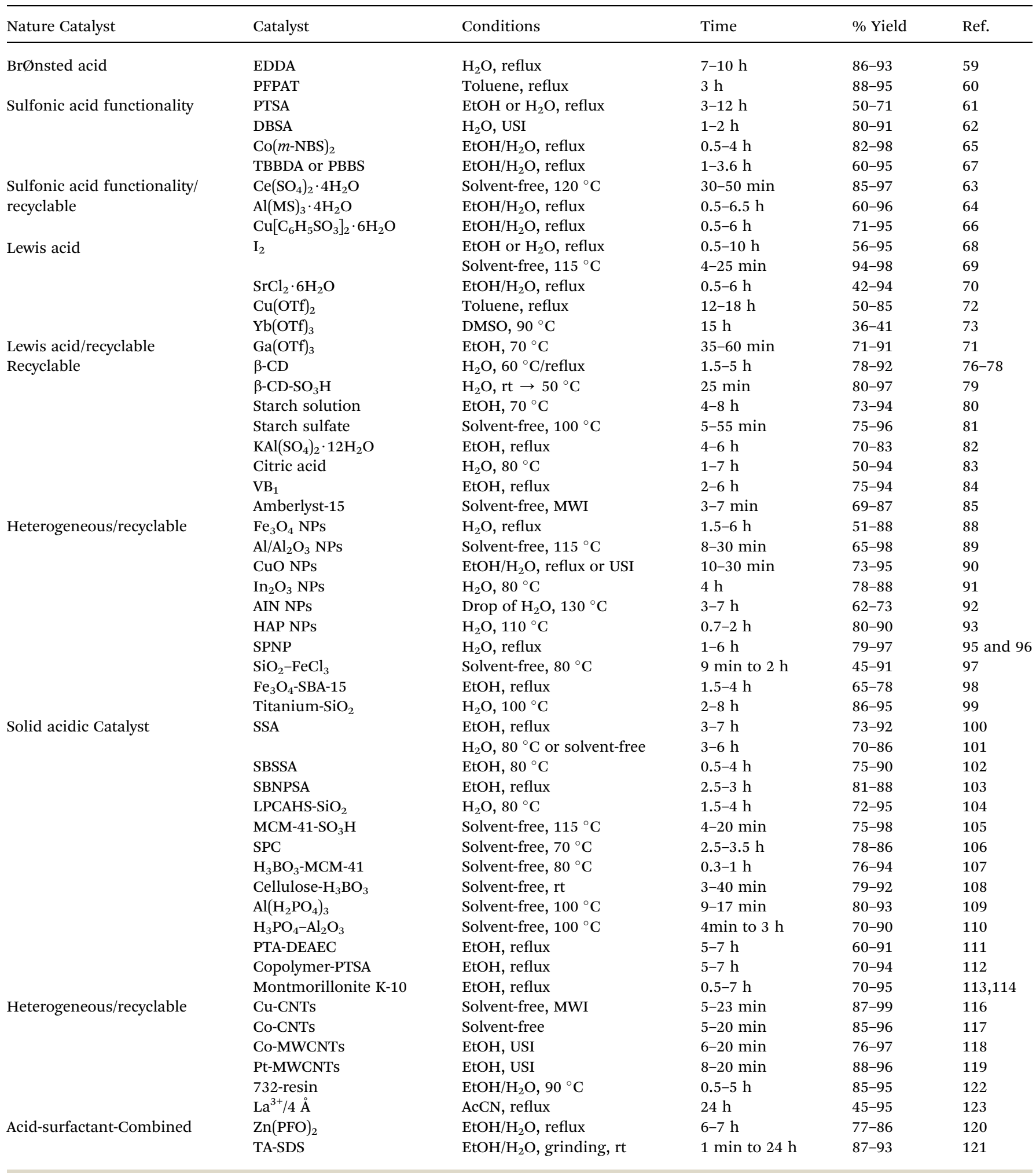

a hydrophobic cavity in the center. Thus, $\beta$-CD is used in numerous applications in drug formulation. It is well known that hydrophobic and van der Waals interactions are involved in the inclusion of complex formation between guest molecules and $\beta$-CD. ${ }^{74}$ Due to its hydrophobic cavity, $\beta$-CD is widely used as a catalyst for a variety of organic reactions, providing a microenvironment whereby it catalyzes reactions through the formation of non-covalent interactions. ${ }^{75} \beta$-CD is a suitable catalyst in the one-pot three-component synthesis of various DHQs producing $78-92 \%$ yield in aqueous media. ${ }^{76-78}$ DHQs 
were also obtained in less than half an hour in the presence of an inexpensive, safe and recyclable sulfonic acid-functionalized $\beta$-CD $\left(\beta-\mathrm{CD}-\mathrm{SO}_{3} \mathrm{H}\right)$ as an efficient catalyst in green media. ${ }^{79}$

Starch is a renewable, biodegradable, and relatively inexpensive material. A starch aqueous solution in EtOH was employed as safe, non-toxic and reusable catalyst for the preparation of DHQ derivatives with $73-94 \%$ yields. ${ }^{80}$ Starch sulfate also reduced the reaction time to less than 1 hour. ${ }^{81}$

Furthermore, alum $\left(\mathrm{KAl}\left(\mathrm{SO}_{4}\right)_{2} \cdot 12 \mathrm{H}_{2} \mathrm{O}\right){ }^{82}$ citric acid, ${ }^{83}$ and thiamine hydrochloride $\left(\mathrm{VB}_{1}\right){ }^{\mathbf{8 4}}$ catalyzed the one-pot threecomponent reaction in aqueous media. The protocols were longer (up to $7 \mathrm{~h}$ ) but reported to be environmentally safe.

Amberlyst-15 is a cationic exchange resin. These types of resins, especially the macroporous ones, are recyclable catalysts for various organic syntheses, including the preparation of DHQs. Amberlyst-15 presents several advantages over conventional catalyst with respect to corrosion, product recovery, and selectivity. ${ }^{85}$

\section{Heterogeneous and reusable catalysts}

Recently, the development of heterogeneous organic reactions has been gaining popularity. They are characterized by ease of handling, separation, recycling, and environmentally safe disposal. ${ }^{86}$ In the last decade, the field of nanoscience and nanotechnology has had tremendous growth. Nanoparticles (NPs) are defined as materials having 1-50 nm diameter, a size range where metals can show size-dependent properties. Because of their interesting structures and high catalytic activities, due to the wide surface/volume ratio that provides many active sites per unit area, NPs and particularly magnetic particles have emerged as useful heterogeneous catalysts in terms of selectivity, reactivity, and improved yields of products. In addition, the magnetic properties of NPs make complete recovery of the catalyst possible by means of an external magnetic field. ${ }^{87}$ As reported in Table 3, some metal and metal oxide NPs, exhibiting high surface/volume ratio, quantum size and quantum tunnel effects, efficiently catalyzed the one-pot three-component synthesis of DHQs, in 0.5-6 h. ${ }^{8-91}$ Nanosized aluminum nitride, a non-toxic, low-cost and highly pure powder, was used as a solid source of ammonia in the multicomponent synthesis of DHQs. ${ }^{92}$ Hydroxyapatite (HAP) NPs show ion-exchange ability, adsorption capacity, and acid-base properties. Because of their higher surface areas and lower particle size, HAP NPs provide greater catalytic activity in the synthesis of DHQs. ${ }^{93}$ Although NPs have advantages such as simplified isolation of the product, easy recyclability and recovery of the catalyst, the naked NPs could aggregate into large clusters, limiting their use. This problem could be solved by immobilizing the NPs on mesoporous substrates characterized by large surface area, high chemical and thermal stability and good compatibility, such as silica, polymers and carbon. ${ }^{\mathbf{9 4}}$ The integration of mesoporous silica with magnetic NPs is certainly of great interest for practical applications. As shown in Table 3, different silica-supported NPs were used as catalysts for the one-pot three-component reaction, leading to $45-97 \%$ yield in 1-8 h. ${ }^{95-99}$ The use of solid acids, as non-toxic, low-cost and reusable catalysts, has also emerged in the synthesis of DHQs (Table 3). Among them, several acids bearing sulfonic moiety supported on silica catalyzed the multi-component synthesis under different conditions, providing DHQs with $>70 \%$ yield in 0.5-7 h. ${ }^{100-104}$ MCM-41 is another type of ordered mesoporous silica material. Various acid-functionalized MCM-41, ${ }^{105-107}$ cellulose,${ }^{108}$ and alumina, ${ }^{\mathbf{1 0 9 , 1 1 0}}$ were used as solid recyclable acidic catalysts for the one-pot three-component synthesis of DHQs, under solvent-free conditions, affording 70-98\% yield in less than 1 hour. On the other hand, solid acids used in refluxing EtOH lengthened the reaction time to 5-7 hours. ${ }^{111,112}$ Montmorillonite K-10 is one of the most important smectites, a phyllosilicate mineral species, used as a catalyst in organic synthesis. It is a clay with both BrØnsted and Lewis acid sites, with a high cation-exchange capacity. Montmorillonite K-10 is considered a solid acid that acts as heterogeneous catalyst for diverse syntheses, including the one-pot three-component cyclocondensation, and can be easily removed from the reaction mixture. ${ }^{\mathbf{1 1 3 , 1 1 4}}$ Other interesting solid supports used in heterogeneous catalysis are carbon nanotubes (CNTs), due to the porosity, inertness, and low interactions between catalyst and support and good mechanical strength. ${ }^{\mathbf{1 1 5}}$ The deposition of metal NPs on the external surface of CNTs and multi-walled CNTs (MWCNTs) are attractive for catalysis, since they increase the reactive surface area. As reported in Table 3, CNTs supporting transition metals efficiently catalyzed the one-pot threecomponent synthesis of DHQs, obtained with 76-99\% yield in less than half an hour. ${ }^{116-119}$ About the same yield was obtained using acid-surfactant-combined catalysts. ${ }^{\mathbf{1 2 0 , 1 2 1}}$ A strong acidic cation-exchange resin (732-resin), ${ }^{122}$ and a $4 \AA$ molecular sieve modified with lanthanum(III) $\left(\mathrm{La}^{3+} / 4 \AA\right),{ }^{123}$ were employed as heterogeneous and recyclable catalysts for the multi-component synthesis of DHQs.

\section{Greener and convenient approaches to obtain DHQ derivatives}

In the new century, there has been an increasing demand for the development of sustainable chemistry. In 1998, Anastas and Warner published the "Twelve Principles of Green Chemistry", ${ }^{124}$ whose main purpose was the pollution prevention. In this regard, green chemistry was committed to (i) decrease pollution-generating chemicals; (ii) limit the use of dangerous chemicals and exhaustible feedstock materials and scarce resources; and (iii) reduce the harmful effects of final products. ${ }^{125-127}$ The development of cleaner and safer chemical processes started with the use of heterogeneous and recyclable catalysts or alternative solvents, which are not volatile, flammable or toxic. Then, it moved to performing reactions under catalyst- and/or solvent-free conditions. Finally, it incorporated the replacement of conventional thermal equipment by nonconventional sources, such as microwave or ultrasound irradiations.

\section{Heterogeneous/recyclable catalysts}

As shown in Table 4 , recyclable catalysts, such as $\beta-C D,{ }^{77}$ amberlyst-15, ${ }^{128}$ and cerous methanesulfonate $\left[\mathrm{Ce}(\mathrm{MS})_{3}\right],{ }^{129}$ 
Table 4 Catalysts for green chemistry approaches to synthesize various DHQs

\begin{tabular}{|c|c|c|c|c|c|}
\hline Nature catalyst & Catalyst & Conditions & Time & $\%$ Yield & Ref. \\
\hline \multirow[t]{2}{*}{ Recyclable } & $\beta-\mathrm{CD}$ & $\mathrm{H}_{2} \mathrm{O}, 60^{\circ} \mathrm{C}$ & $1.5 \mathrm{~h}$ & $78-92$ & 77 \\
\hline & Amberlyst-15 & $\mathrm{CH}_{3} \mathrm{CN}, 80^{\circ} \mathrm{C}$ & $10-30 \mathrm{~min}$ & $96-98$ & 128 \\
\hline \multirow[t]{16}{*}{ Solid acid } & Sulfamic acid & $\mathrm{H}_{2} \mathrm{O}, 60^{\circ} \mathrm{C}$ or $\mathrm{MeOH}, \mathrm{rt}$ & $15-180 \mathrm{~min}$ & $57-95$ & 130 \\
\hline & $\mathrm{H}_{2} \mathrm{SO}_{4}-\mathrm{SiO}_{2}$ & $\mathrm{rt}$ & $0.2-5 \mathrm{~h}$ & $93-97$ & 131 \\
\hline & $\mathrm{PPA}_{-\mathrm{SiO}_{2}}$ & Solvent-free, $\mathrm{rt}$ & $1.5-4 \mathrm{~h}$ & $89-93$ & 132 and 133 \\
\hline & $\mathrm{CAN} \cdot \mathrm{SiO}_{2}$ & $\mathrm{CH}_{3} \mathrm{CN}, \mathrm{rt}$ & $10-50 \mathrm{~min}$ & $78-94$ & 136 \\
\hline & Boehmite-SSA & $\mathrm{EtOH}, 80^{\circ} \mathrm{C}$ & $35-130 \mathrm{~min}$ & $85-96$ & 137 \\
\hline & Boehmite-Si-DSA & EtOH, reflux & $30-190 \mathrm{~min}$ & $92-98$ & 138 \\
\hline & Montmorillonite KSF & $\mathrm{CH}_{3} \mathrm{CN}, \mathrm{rt}$ & $20-50 \mathrm{~min}$ & $90-99$ & 139 \\
\hline & HCNC-4 & $\mathrm{CH}_{3} \mathrm{CN}, \mathrm{rt}$ & $15-30 \mathrm{~min}$ & $82-99$ & 140 \\
\hline & Cellulose- $\mathrm{SO}_{3} \mathrm{H}$ & $\mathrm{CH}_{3} \mathrm{CN}, \mathrm{rt}$ & $40-60 \mathrm{~min}$ & $77-92$ & 141 \\
\hline & $\mathrm{SO}_{4}{ }^{2-} / \mathrm{ZrO}_{2}$ & EtOH, reflux & $7-160 \mathrm{~min}$ & $84-96$ & 146 \\
\hline & $\mathrm{Zr}(\mathrm{DS})_{4}$ & $\mathrm{H}_{2} \mathrm{O}, \mathrm{rt}$ & $8-45 \min$ & $83-97$ & 147 \\
\hline & $p$-SAC & $\mathrm{H}_{2} \mathrm{O}, \mathrm{rt}$ & $18-90 \mathrm{~min}$ & $64-94$ & 148 \\
\hline & $\mathrm{H}_{3} \mathrm{PW}_{12} \mathrm{O}_{40}$ & $\mathrm{H}_{2} \mathrm{O}, \mathrm{rt}$ & $8-10 \min$ & $79-97$ & 149 \\
\hline & $\mathrm{H}_{3} \mathrm{PW}_{12} \mathrm{O}_{40}$ & $\mathrm{EtOH} / \mathrm{H}_{2} \mathrm{O}, 80^{\circ} \mathrm{C}$ & $12-18 \mathrm{~h}$ & $71-94$ & 140 \\
\hline & $\mathrm{SiO}_{2}-\mathrm{H}_{3} \mathrm{PW}_{12} \mathrm{O}_{40}$ & EtOH, reflux & $5-40 \mathrm{~min}$ & $88-98$ & 151 \\
\hline & Poly(VPyPS)-PW & EtOH, USI & $6-16 \min$ & $74-96$ & 152 \\
\hline \multirow{5}{*}{$\begin{array}{l}\text { Organocatalyst heterogeneous/ } \\
\text { recyclable }\end{array}$} & $\alpha$-Chymotrypsin & $\mathrm{EtOH}, 60^{\circ} \mathrm{C}$ & $30-60 \min$ & $90-98$ & 153 \\
\hline & $\mathrm{Fe}_{3} \mathrm{O}_{4}-\mathrm{GO}$ & EtOH, reflux & $2.5-5 \mathrm{~h}$ & $70-80$ & 154 \\
\hline & GO nanosheets & $\mathrm{H}_{2} \mathrm{O}, \mathrm{rt}$ & $10-30 \mathrm{~min}$ & $85-97$ & 155 \\
\hline & Co-CNTs & Solvent-free, MWI & 10-35 min & $75-98$ & 156 \\
\hline & Ag-CNTs & EtOH, USI & $5-21 \mathrm{~min}$ & $86-97$ & 157 \\
\hline
\end{tabular}

have been used for the cyclocondensation of anthranilamide and aldehydes. In general, the use of heterogeneous and reusable catalysts afforded high yields, up to $99 \%$, in very short times. A number of solid acid catalysts, on various supports, such as silica, ${ }^{130-138}$ and clay, ${ }^{139,140}$ as well as different catalysts bearing sulfonic acid groups and anchored on cellulose, ${ }^{141}$ Wang resin, ${ }^{142}$ NPs, ${ }^{143,144}$ and other supports, ${ }^{145,146}$ were employed. Reusable acid-surfactantcombined catalysts, ${ }^{\mathbf{1 4 7}, \mathbf{1 4 8}}$ and heteropolyacids, ${ }^{\mathbf{1 4 9 - 1 5 2}}$ have also emerged as good catalysts, due to their unique properties like high thermal stability, low cost, ease of preparation and recovery. They efficiently catalyze the synthesis of DHQs in aqueous media in 5-90 min.

Enzymes have received great attention as sustainable and biodegradable catalysts for the synthesis of biologically active compounds. Among them, $\alpha$-chymotrypsin rapidly catalyzes the cyclocondensation of anthranilamide and aldehydes with 9098\% yield. ${ }^{153}$ Transition metal-based heterogeneous systems were efficiently used as recyclable catalysts for the cyclocondensation of anthranilamide and aldehydes, yielding $>70 \%$ DHQs. ${ }^{154-161}$

\section{Alternative solvents}

The choice of the solvent for a desired chemical process can have profound economic and environmental consequences. For this reason, there has been significant interest in using alternative "clean" solvents, mostly aqueous media and ionic liquids. Water is readily available, cheap, non-toxic, nonflammable and is very attractive from both an economical and environmental point of view. ${ }^{162}$ The use of ionic liquids as reaction media and catalysts also gives a solution to solvent emission and catalyst-recycling problems. Ionic liquids present many important features, such as negligible vapor pressure, non-inflammability, immiscibility with non-polar solvents, reasonable thermal and chemical stability and recyclability. ${ }^{163}$

Various catalysts were used in aqueous media to synthesize DHQ derivatives, both from the cyclocondensation of anthranilamide and aldehydes, and the one-pot three-component reaction. A hydrotropic solution ${ }^{164}$ and a deep eutectic solvent ${ }^{165}$ were used under catalyst-free conditions (Table 5). Ionic liquids were also widely employed for the synthesis of DHQ derivatives, in different reaction conditions (Table 6). Imidazolium-based ionic liquids $\mathrm{s}^{30,31,46,166-171}$ afforded DHQ derivatives with $70-99 \%$ yield, in $0.5-10 \mathrm{~h}$ unless used under 
Table 5 Alternative solvents: aqueous media for greener approaches to synthesize of DHQs

\begin{tabular}{|c|c|c|c|c|c|}
\hline Nature solvent & Solvent & Conditions & Time & $\%$ Yield & Ref. \\
\hline \multirow[t]{24}{*}{ Aqueous medium } & \multirow[t]{2}{*}{ Aq. EtOH (50\%) } & MES, MWI & $5-20 \mathrm{~min}$ & $83-96$ & 22 \\
\hline & & Sulfanilic acid, $70^{\circ} \mathrm{C}$ & & & 23 \\
\hline & \multirow[t]{8}{*}{$\mathrm{EtOH} / \mathrm{H}_{2} \mathrm{O}$} & $\mathrm{Al}(\mathrm{MS})_{3} \cdot 4 \mathrm{H}_{2} \mathrm{O}$, reflux & $0.5-6.5 \mathrm{~h}$ & $60-96$ & 64 \\
\hline & & $\mathrm{Co}(m-\mathrm{NBS})_{2}$, reflux & $0.5-4 \mathrm{~h}$ & $82-98$ & 65 \\
\hline & & $\mathrm{Cu}\left[\mathrm{C}_{6} \mathrm{H}_{5} \mathrm{SO}_{3}\right]_{2} \cdot 6 \mathrm{H}_{2} \mathrm{O}$, reflux & $0.5-6 \mathrm{~h}$ & $71-95$ & 66 \\
\hline & & CuO NPs, reflux or USI & $10-30 \mathrm{~min}$ & $73-95$ & 90 \\
\hline & & $\mathrm{Zn}(\mathrm{PFO})_{2}$, reflux & $6-7 \mathrm{~h}$ & $77-86$ & 120 \\
\hline & & TA-SDS, grinding, rt & $1 \mathrm{~min}-24 \mathrm{~h}$ & $87-93$ & 121 \\
\hline & & 732-resin, $90^{\circ} \mathrm{C}$ & $0.5-5 \mathrm{~h}$ & $85-95$ & 122 \\
\hline & & $\mathrm{H}_{3} \mathrm{PW}_{12} \mathrm{O}_{40}, 80^{\circ} \mathrm{C}$ & $12-18 \mathrm{~h}$ & $71-94$ & 150 \\
\hline & EtOH or $\mathrm{H}_{2} \mathrm{O}$ & PTSA, rflux & $3-12 \mathrm{~h}$ & $50-71$ & 61 \\
\hline & \multirow{13}{*}{$\mathrm{H}_{2} \mathrm{O}$} & EDDA, reflux & $7-10 \mathrm{~h}$ & $86-93$ & 59 \\
\hline & & DBSA, USI & $1-2 \mathrm{~h}$ & $80-91$ & 62 \\
\hline & & $\beta$-CD, $60^{\circ} \mathrm{C} /$ reflux & $1.5-5 \mathrm{~h}$ & $78-92$ & $76-78$ \\
\hline & & $\beta-\mathrm{CD}-\mathrm{SO}_{3} \mathrm{H}, \mathrm{rt} \rightarrow 50{ }^{\circ} \mathrm{C}$ & $25 \mathrm{~min}$ & $80-97$ & 79 \\
\hline & & $\mathrm{CA}, 80^{\circ} \mathrm{C}$ & $1-7 \mathrm{~h}$ & $50-94$ & 83 \\
\hline & & Magnetic $\mathrm{Fe}_{3} \mathrm{O}_{4}$ NPs, reflux & $1.5-6 \mathrm{~h}$ & $51-88$ & 88 \\
\hline & & $\mathrm{In}_{2} \mathrm{O}_{3}$ NPs, $80^{\circ} \mathrm{C}$ & $4 \mathrm{~h}$ & $78-88$ & 91 \\
\hline & & HAP NPs, $110{ }^{\circ} \mathrm{C}$ & $0.7-2 \mathrm{~h}$ & $80-90$ & 93 \\
\hline & & SPNP, reflux & $1-6 \mathrm{~h}$ & $79-97$ & 95 and 96 \\
\hline & & Titanium-SiO ${ }_{2}, 100{ }^{\circ} \mathrm{C}$ & $2-8 \mathrm{~h}$ & $86-95$ & 99 \\
\hline & & SSA, $80^{\circ} \mathrm{C}$ & $3-6 \mathrm{~h}$ & $70-86$ & 101 \\
\hline & & $L$ PCAHS- $\mathrm{SiO}_{2}, 80^{\circ} \mathrm{C}$ & $1.5-4 \mathrm{~h}$ & $72-95$ & 104 \\
\hline & & GO nanosheets, rt & $10-30 \mathrm{~min}$ & $85-97$ & 155 \\
\hline Hydrotropic solution & NaPTS (50\%) & Catalyst-free, $60{ }^{\circ} \mathrm{C}$ & 50-95 $\min$ & $78-95$ & 164 \\
\hline Deep eutectic solvent & L-(+)-TA-DMU & Catalyst-free, $90^{\circ} \mathrm{C}$ & $4 \mathrm{~h}$ & 79 & 165 \\
\hline
\end{tabular}

microwave irradiation (MWI). ${ }^{172}$ The triazolium-based reactions take less than half an hour to complete the one-pot threecomponent reaction. ${ }^{173}$ Ionic liquids bearing sulfonic acid functionality were used under solvent-free conditions and rapidly catalyzed the synthesis of DHQs. ${ }^{174,175}$ Although basic ionic liquids ${ }^{171-178}$ and a glycerol based ionic liquid with a boron core ${ }^{179}$ were also used under solvent-free conditions, they catalyzed the reaction in a longer time (10-90 min).

\section{Catalyst- and solvent-free reactions}

The challenge for a sustainable environment requires the development of greener and cleaner chemical processes that can avoid the use of harmful solvents and catalysts. In this sense, new strategies have been developed to synthesize DHQ derivatives in solvent- and/or catalyst-free conditions (Table 7). The cyclocondensation of anthranilamide and aldehydes was performed in the presence of sodium dihydrogen phosphate $\left(\mathrm{NaH}_{2} \mathrm{PO}_{4}\right),{ }^{180}$ acidic catalysts, ${ }^{181-183}$ and various heterogeneous systems, under solvent-free conditions, leading to various DHQs with $50-98 \%$ yield in a few minutes. On the contrary, a simple and environmentally benign procedure, without any catalyst, lengthened the reaction time to hours, although producing similar yield. ${ }^{184-192}$ The one-pot three-component reaction was also efficiently performed under solvent-free conditions in the presence of heterogeneous catalysts using conventional heating or MWI. The absence of catalyst again afforded $74-97 \%$ yield but in longer reaction times (1-6 h). ${ }^{193-197}$ Urea or thiourea was used in the multi-component synthesis of DHQs as the ammonia surrogate under catalyst-free conditions. ${ }^{198}$ A very efficient and fast synthesis of DHQs was attempted under both catalyst- and solvent-free conditions (>90\% yield, in 3-10 min)..$^{199,200}$ 
Table 6 Alternative solvents: ionic liquids for green chemistry approaches to synthesize various DHQs

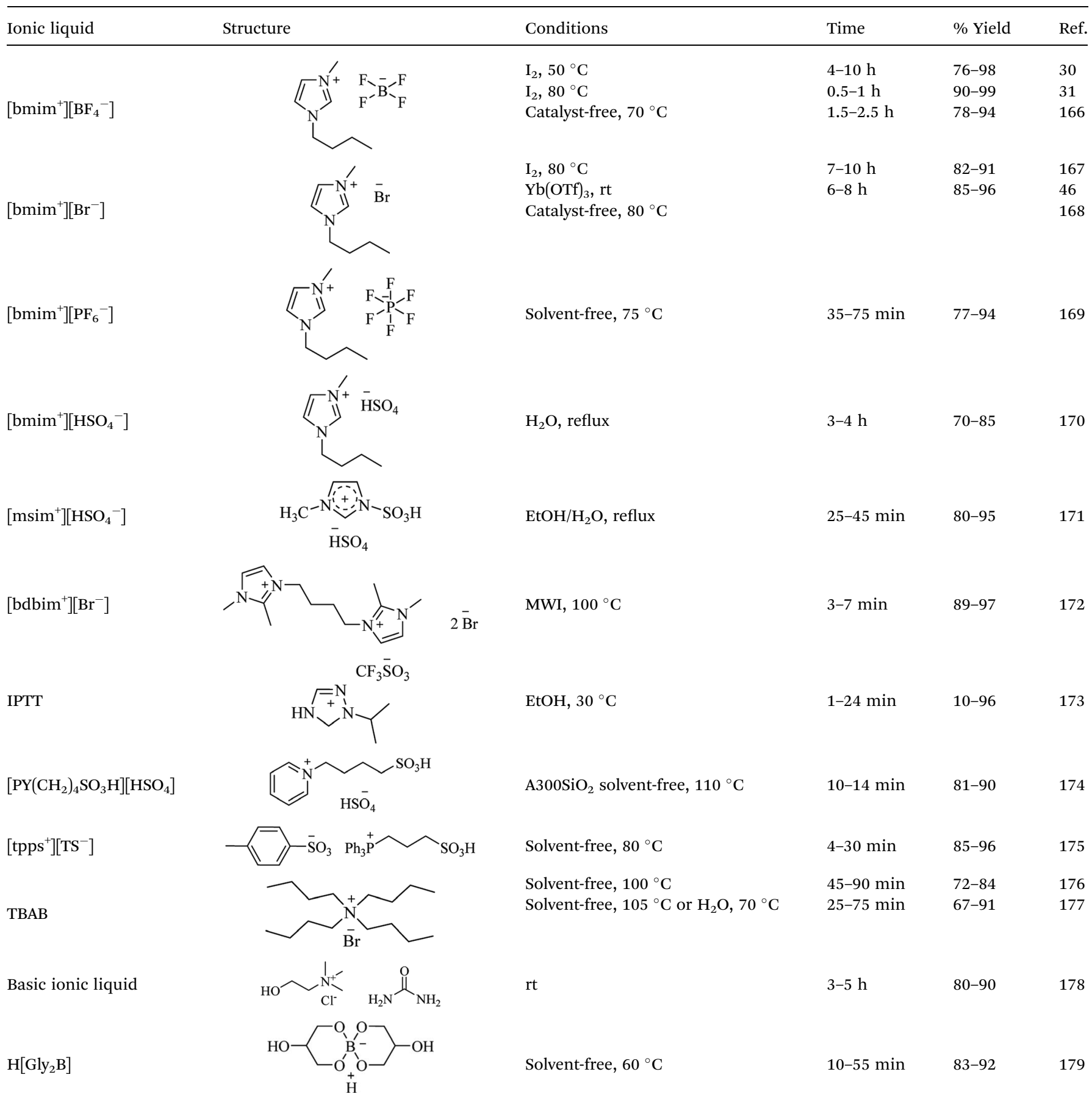

\section{New energy sources: microwave and ultrasound irradiations}

MWI in organic synthesis is commonly used because it facilitates heat transfer better in chemical reactions. The efficiency of MWI heating results in a dramatic reduction in reaction times to minutes as compared to conventional heating methods taking several hours. From an economic and environmental viewpoint, the use of MWI provides unique chemical processes, characterized by enhanced reaction rates, sometimes higher yields, greater selectivity, and ease of manipulation. ${ }^{201,202}$ Previously, efforts were made to synthesize DHQs under MWI
(Table 8). Among them, the cyclocondensation of anthranilamide, under acidic catalysis, ${ }^{203}$ as well as the one-pot threecomponent reaction, in the presence of $\mathrm{L}$-proline in water. ${ }^{204}$ The ultrasound irradiation (USI)-assisted reactions have also become increasingly popular in organic synthesis. Due to faster reactions, MWI and USI allow the elimination or minimization of side products formation. They are frequently used in the pharmaceutical industry and may pave the way towards a greener and more sustainable approach to chemical synthesis. ${ }^{205}$ A variety of organic reactions were carried out 
Table 7 Catalyst- and/or solvent-free synthesis of DHQs

\begin{tabular}{|c|c|c|c|c|c|}
\hline Reaction & Catalyst & Conditions & Time & $\%$ Yield & Ref. \\
\hline \multirow[t]{13}{*}{ Cyclocondensation } & $\mathrm{H}_{2} \mathrm{SO}_{4}$ & Solvent-free, MWI & Few min & $68-78$ & 17 \\
\hline & $\mathrm{H}_{3} \mathrm{BO}_{3}$ & Solvent-free, $120^{\circ} \mathrm{C}$ & $5 \mathrm{~min}$ & $82-90$ & 28 \\
\hline & Cellulose- $\mathrm{H}_{3} \mathrm{BO}_{3}$ & Solvent-free, rt & $3-40 \mathrm{~min}$ & $79-92$ & 108 \\
\hline & Co-CNTs & Solvent-free, $\mathrm{rt}$ & $5-20 \mathrm{~min}$ & $85-96$ & 117 \\
\hline & $\mathrm{PPA}_{-} \mathrm{SiO}_{2}$ & Solvent-free, rt & $1.5-4 \mathrm{~h}$ & $89-93$ & 132 \\
\hline & Citric acid & Solvent-free, grinding & $10-20 \mathrm{~min}$ & $65-98$ & 181 \\
\hline & Lemon juice & Solvent-free, $\mathrm{rt}$ & $7-10 \mathrm{~min}$ & $82-85$ & 182 \\
\hline & Lactic acid & Solvent-free, $70{ }^{\circ} \mathrm{C}$ & $0.3-6 \mathrm{~h}$ & $80-92$ & 183 \\
\hline & Catalyst-free & L-(+)-TA-DMU, $90^{\circ} \mathrm{C}$ & $4 \mathrm{~h}$ & 79 & 165 \\
\hline & & $\mathrm{AcOH}, \mathrm{rt}$ & $4 \mathrm{~h}$ & $35-49$ & 184 \\
\hline & & Dry $\mathrm{MeOH}$, reflux & $5 \mathrm{~h}$ & $55-73$ & 185 \\
\hline & & $\mathrm{H}_{2} \mathrm{O}, 90^{\circ} \mathrm{C}$ & $1-6 \mathrm{~h}$ & $67-94$ & 190 and 191 \\
\hline & & $\mathrm{H}_{2} \mathrm{O}$, reflux & $0.5-27 \mathrm{~h}$ & $73-99$ & 192 \\
\hline \multirow[t]{15}{*}{ One-pot Three-component } & $\mathrm{Ce}\left(\mathrm{SO}_{4}\right)_{2} \cdot 4 \mathrm{H}_{2} \mathrm{O}$ & Solvent-free, $120^{\circ} \mathrm{C}$ & $30-50 \mathrm{~min}$ & $85-97$ & 63 \\
\hline & $\mathrm{I}_{2}$ & Solvent-free, $115^{\circ} \mathrm{C}$ & $4-25 \min$ & $94-98$ & 69 \\
\hline & Starch sulfate & Solvent-free, $100^{\circ} \mathrm{C}$ & 5-55 min & $75-96$ & 81 \\
\hline & Amberlyst-15 & Solvent-free, MWI & $3-7 \mathrm{~min}$ & $69-87$ & 85 \\
\hline & $\mathrm{Al} / \mathrm{Al}_{2} \mathrm{O}_{3} \mathrm{NPs}$ & Solvent-free, $115^{\circ} \mathrm{C}$ & $8-30 \mathrm{~min}$ & $65-98$ & 89 \\
\hline & $\mathrm{SiO}_{2}-\mathrm{FeCl}_{3}$ & Solvent-free, $80{ }^{\circ} \mathrm{C}$ & $9-120 \mathrm{~min}$ & $45-91$ & 97 \\
\hline & SSA & Solvent-free, rt & $3-6 \mathrm{~h}$ & $70-86$ & 101 \\
\hline & MCM-41- $\mathrm{SO}_{3} \mathrm{H}$ & Solvent-free, $115^{\circ} \mathrm{C}$ & $4-20 \mathrm{~min}$ & $75-98$ & 105 \\
\hline & SPC & Solvent-free, $70^{\circ} \mathrm{C}$ & $2.5-3.5 \mathrm{~h}$ & $78-86$ & 106 \\
\hline & Cellulose- $\mathrm{H}_{3} \mathrm{BO}_{3}$ & Solvent-free, rt & $3-40 \mathrm{~min}$ & $79-92$ & 108 \\
\hline & & PEG-400, $120-125^{\circ} \mathrm{C}$ & $1-6 \mathrm{~h}$ & $80-97$ & 196 \\
\hline & & Glycerol, $80^{\circ} \mathrm{C}$ & $2 \mathrm{~h}$ & $88-90$ & 197 \\
\hline & & EtOH, reflux & $6 \mathrm{~h}$ & $80-92$ & 198 \\
\hline & & Solvent-free, $70^{\circ} \mathrm{C}$ & $10 \mathrm{~min}$ & $87-96$ & 199 \\
\hline & & Solvent-free, $120^{\circ} \mathrm{C}$ or MWI & $3 \mathrm{~min}$ & $90-97$ & 200 \\
\hline
\end{tabular}

within short times under USI, including the synthesis of DHQs, in the presence of amberlyst-15 (ref. 206) and in other different conditions (Table 8).

\section{Alternative synthetic strategies}

Although the cyclocondensation of anthranilamide and the one-pot three-component reaction of isatoic anhydrides, ammonium acetates and aldehydes are the main ways to synthesize DHQ derivatives, other synthetic strategies have also been developed (Table 9).

\section{Cyclocondensation of anthranilamide and different substrates}

Anthranilamide was the most common starting material for the preparation of DHQs. Other than aldehydes, other substrates were used for the cyclocondensation with anthranilamide in different conditions to give DHQ derivatives (Scheme 6).

First, the cyclocondensation of anthranilamide and oxocompounds, such as benzil, ${ }^{207}$ 2-oxo(alkyl)acetates, ${ }^{208}$ and $4^{\prime}$ bromoacetophenone, ${ }^{209}$ were attempted to give DHQs in different conditions. The obtained 2,2-disubstituted DHQ was then cleaved in ethanolic/methanolic hydroxide to give the respective derivative. Alcohols were used in a rutheniumcatalyzed cyclocondensation with anthranilamide. ${ }^{210}$ Cyclocondensations of anthranilamide and gem-dibromomethylarenes, as aldehyde equivalents, were performed in the presence of potassium tert-butoxide ( $t$-BuOK), in anhydrous pyridine and $N, N$-dimethylformamide (DMF). ${ }^{211}$ Anthranilamide also reacts with dicyanoepoxide to give DHQs in refluxing $\mathrm{CH}_{3} \mathrm{CN}^{212}$ 
Table 8 New energy sources for greener approaches to synthesize DHQs

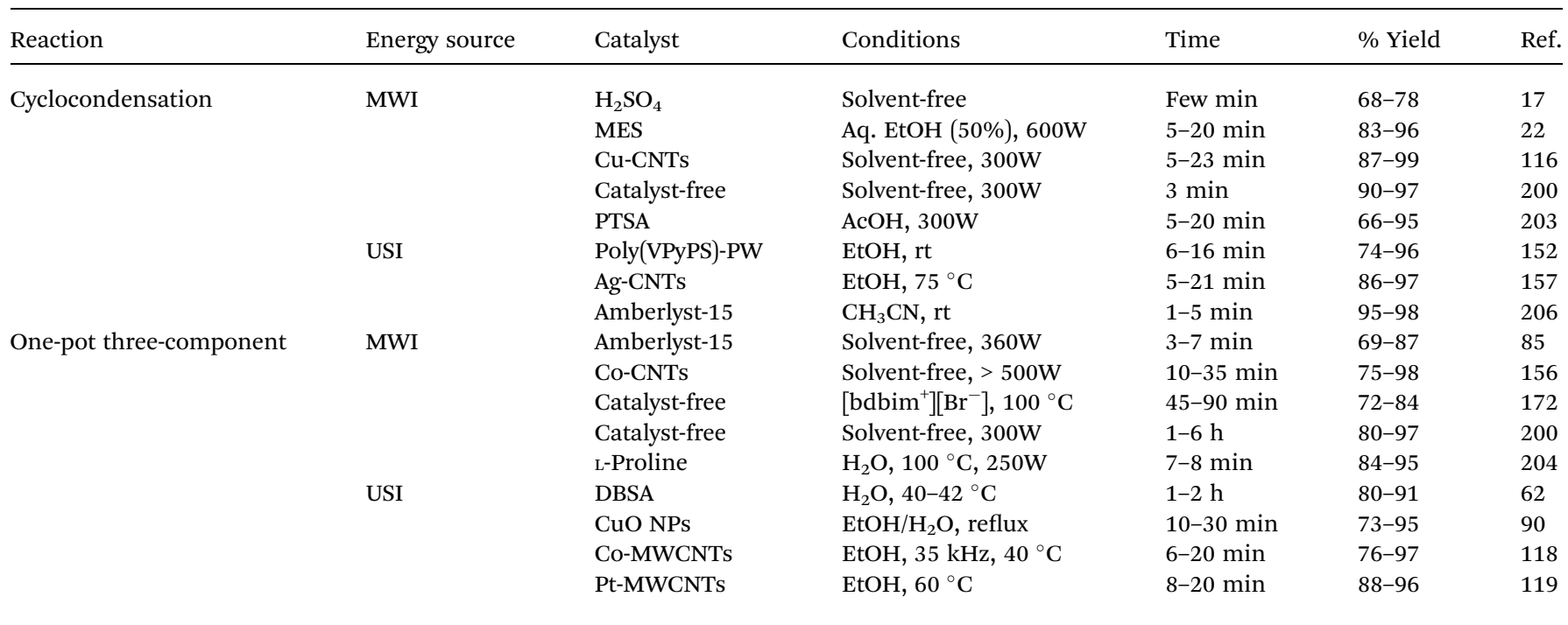

Table 9 Reaction conditions for the alternative synthetic strategies

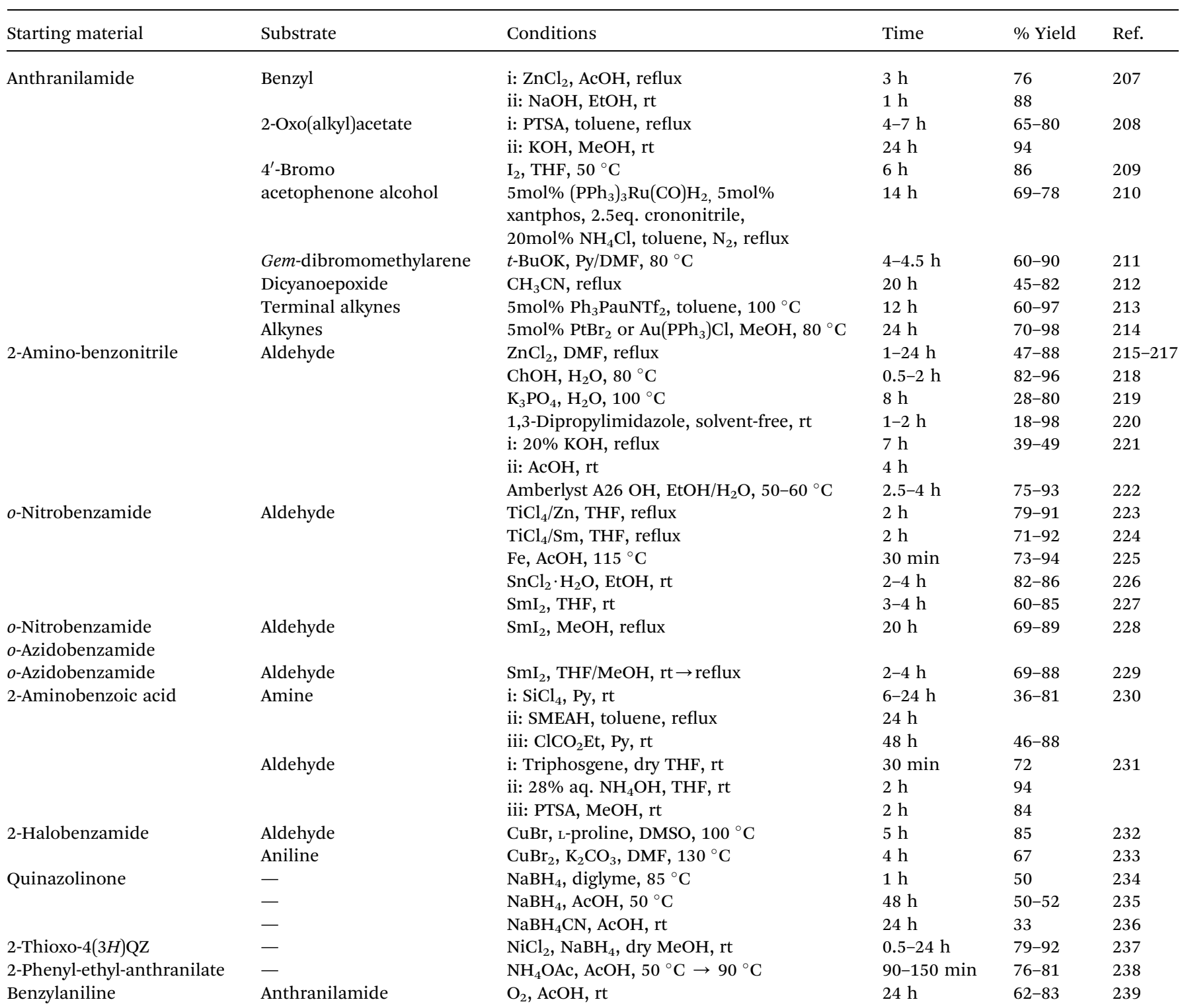




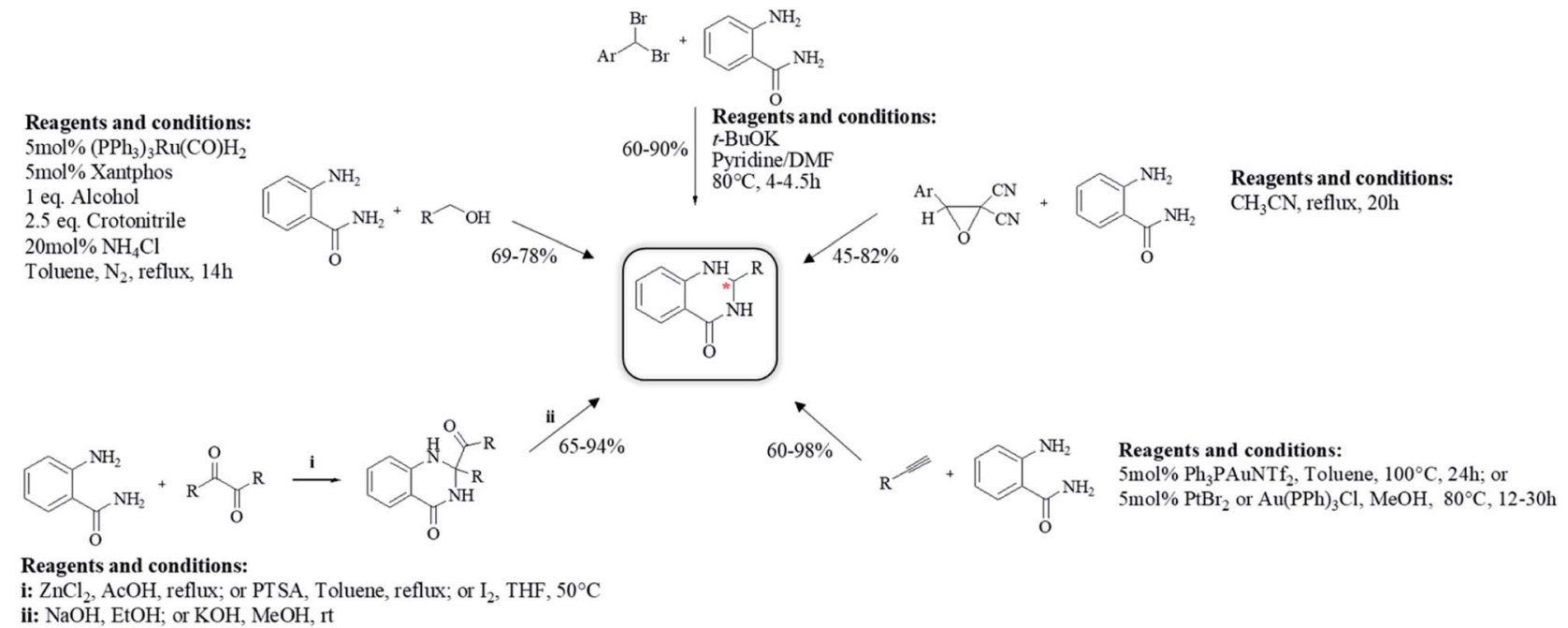

Scheme 6 Alternative synthetic strategies of cyclocondensation of anthranilamide and different substrates.

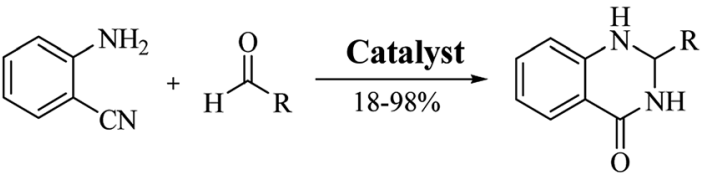

Scheme 7 Cyclocondensation of 2-aminobenzonitrile and an aldehyde for the preparation of DHQs.

The direct hydroamination/hydroarylation and double hydroamination of alkynes, followed by the cyclocondensation with anthranilamide was also exploited for the synthesis of DHQ derivatives. ${ }^{\mathbf{2 1 3 , 2 1 4}}$ These alternative strategies afforded DHQs with $45-97 \%$ yield in 1-24 h (Table 9).

\section{Reductive cyclocondensation of 2-aminobenzonitrile/o- nitrobenzamide/o-azidobenzamide and aldehydes}

An alternative method starting from 2-aminobenzonitrile and aldehydes was developed to synthesize DHQs (Scheme 7) and two plausible mechanisms have been proposed. The first was the formation of a Schiff base and subsequent cyclocondensation in the presence of various catalysts (Scheme 8a), yielding $18-98 \%$ DHQs in $0.5-8 \mathrm{~h}$ (Table 9). ${ }^{215-220}$ The second proposed mechanism was the hydration of the 2-aminobenzonitrile to anthranilamide in different conditions (Scheme $8 \mathrm{~b})$ by means of potassium hydroxide $(\mathrm{KOH}),{ }^{221}$ or amberlyst A26 OH. ${ }^{222}$

The reductive cyclization of $o$-nitrobenzamide $\mathrm{e}^{223-227}$ and/or $o$ azidobenzamide ${ }^{228,229}$ and aldehydes yield DHQ derivatives in the presence of metallic catalysts with 60-94\% yield in short reaction times (Scheme 9; Table 9).

\section{Other strategies}

Other strategies have been developed to synthesize DHQ derivatives starting from various substrates (Scheme 10) giving 39-94\% yield in $0.5-48 \mathrm{~h}$ (Table 9). One such method employed 2-aminobenzoic acid as a starting material to prepare DHQ derivatives. The condensation of the 2-aminobenzoic acid with amines in the presence of $\mathrm{SiCl}_{4}$ led to the corresponding substituted anthranilamides, subsequently reduced with sodium bis(2-methoxyethoxy)-aluminum hydride to $o$-aminobenzylamines. Then, the latter compounds were cyclized into DHQs by means of ethylchloroformate/pyridine. ${ }^{230}$ Another strategy converted the 2-aminobenzoic acid in isatoic anhydride by means of triphosgene in dry THF, then converted to anthranilamide using $28 \% \quad \mathrm{NH}_{4} \mathrm{OH}$ solution. The cyclocondensation with the aldehyde in the presence of $p$-toluenesulfonic acid, in refluxing $\mathrm{MeOH}$, gave the respective DHQ. ${ }^{231}$ The copper-catalyzed cyclocondensation of 2-halobenzamide and aldehyde in the presence of aqueous ammonia, ${ }^{232}$ and 2halobenzamide with anilines, ${ }^{233}$ also gave DHQs derivatives. DHQs could also be prepared by reduction from $4(3 H)$-quinazolinones (QZs) with $\mathrm{NaBH}_{4},{ }^{234,235}$ or $\mathrm{NaBH}_{4} \mathrm{CN}{ }^{236}$ DHQs were also obtained by reductive desulfurization of 2-thioxo-4(3H)quinazolinones with nickel boride, using nickel(II) chloride $\left(\mathrm{NiCl}_{2}\right)$ and $\mathrm{NaBH}_{4} \cdot{ }^{237}$ The intramolecular cyclization of 2phenyl-ethyl anthranilate in the presence of $\mathrm{NH}_{4} \mathrm{OAc}$ led to the respective DHQs. ${ }^{238}$ The oxidation of benzylamines to the corresponding $\mathrm{N}$-benzylbenzaldimines was also investigated and used for the synthesis of DHQ derivatives. ${ }^{239}$

\section{Enantioselective synthesis of DHQ derivatives}

Most of the reported methods allow the synthesis of DHQ derivatives as racemic mixtures. In certain examples, the $(S)$ enantiomer of DHQs had better antiproliferative activity, compared to the $(R)$-enantiomer, even though the racemic mixture showed a similar potency to the pure $S$-enantiomer. ${ }^{3}$ Chinigo et al. first proved that a $(S)$-enantiomer of DHQ binds to tubulin, showing antiproliferative activity in different cancer cell lines. They obtained the pure (S)-enantiomer using trifluoracetic acid in $\mathrm{CH}_{3} \mathrm{CN}$ with $34-86 \%$ yield and $79-91 \%$ enantiomeric excess percentage (ee\%) in 1.5 h. ${ }^{3}$ Although the 


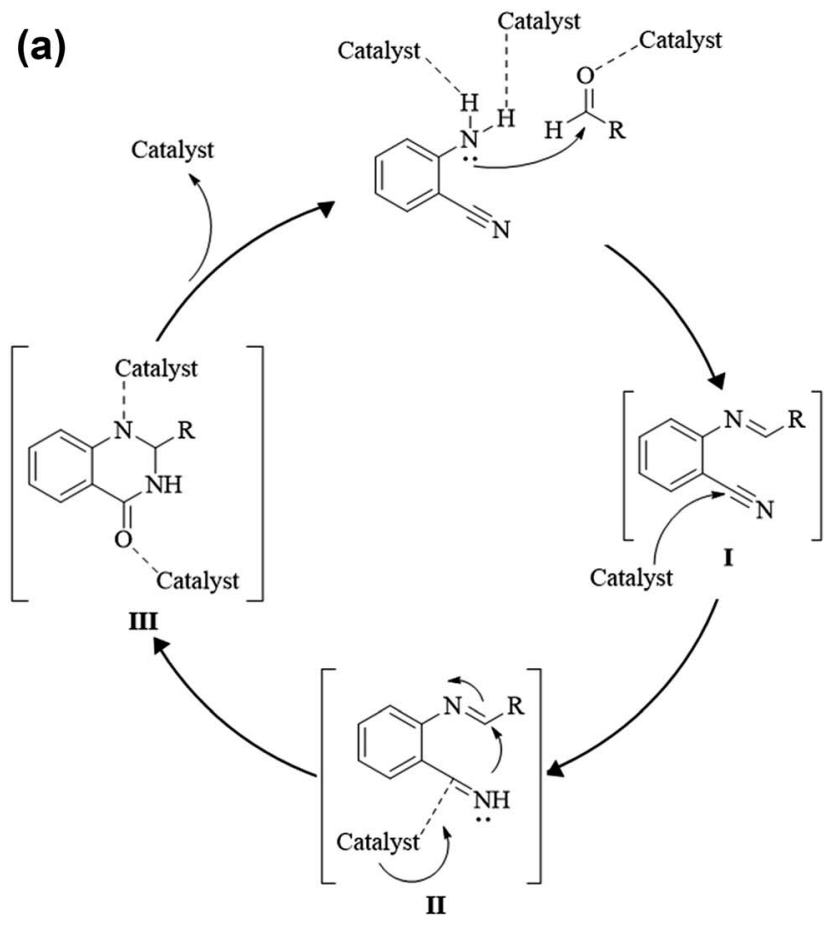

(b)
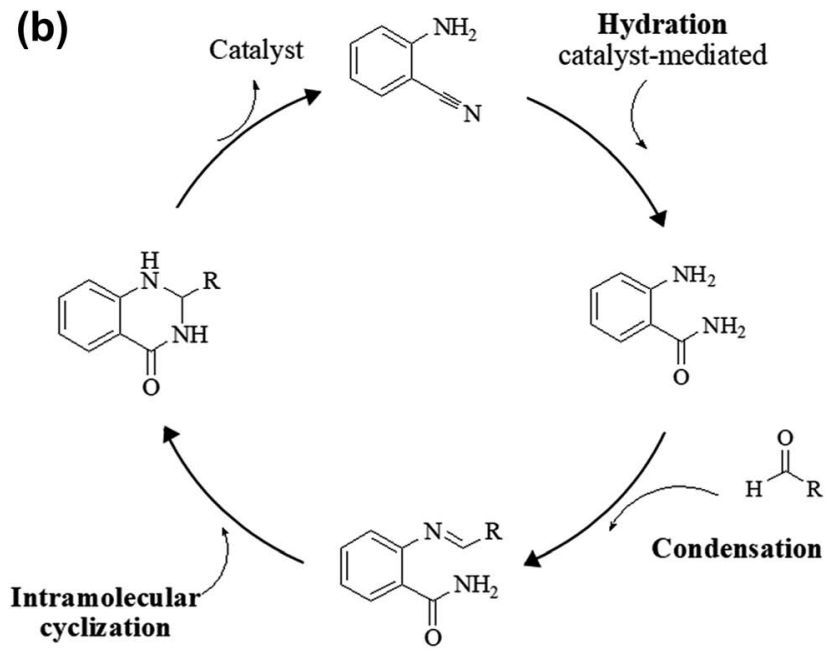

Scheme 8 (a) Plausible mechanism of the cyclocondensation of 2aminobenzonitrile and an aldehyde through formation of Schiff base. (b) Plausible mechanism of the cyclocondensation of 2-aminobenzonitrile and an aldehyde through hydration to anthranilamide.

enantioselective synthesis of DHQs is difficult due to an unstable aminal stereo-center that is sensitive to racemization, some asymmetric strategies have been developed to obtain pure

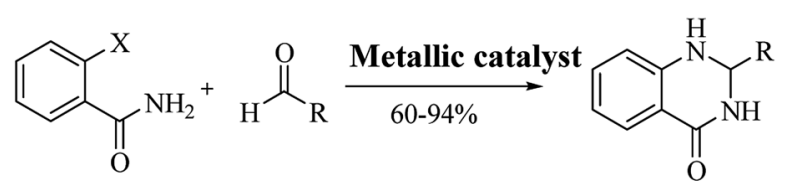

X: $\mathrm{NO}_{2}, \mathrm{~N}_{3}$

Scheme 9 Reductive cyclocondensation of O-nitrobenzamide/oazidobenzamide and an aldehyde.
$(S)$-enantiomers of DHQs (Table 10). Mainly, they consist of the cyclocondensation of anthranilamide and aldehydes in the presence of chiral catalysts that promote the formation of pure enantiomers, or the intramolecular amidation of $N$-Boc imines and anthranilamide (Scheme 11). The use of chiral phosphoric acidic catalysts is common in the enantioselective synthesis of DHQs, although they need a longer time (15-48 h) to complete the reaction. Various chiral phosphoric acids were employed to catalyze the cyclocondensation of anthranilamide and aldehydes, ${ }^{240-243}$ affording 67-99\% yield and 26-99 ee\%. An amidation of $N$-Boc imines and anthranilamide, ${ }^{\mathbf{2 4 4 , 2 4 5}}$ gave pure $(S)$ enantiomer in 10-96 ee\%. Scandium(III)-catalytic systems were also effectively employed for the enantioselective cyclocondensation of anthranilamide and an aldehyde (Table 10). ${ }^{246,247}$

\section{DHQ as an intermediate in organic chemistry}

In addition to their many significant pharmacological activities, DHQs also play a central role as intermediates in organic synthesis. In particular, they can be easily oxidized to the biologically active QZs. The quinazolinone ring (Fig. 4) is frequently encountered in organic chemistry as well as in medicinal chemistry. ${ }^{\mathbf{2 4 8 - 2 5 4}}$ The QZ core is present in the structure of numerous natural products, especially alkaloids, ${ }^{255,256}$ and in some drugs, ${ }^{257}$ exhibiting various pharmacological properties. QZs also represent a privileged scaffold and many protocols are reported in literature for the synthesis of this important synthon. Among them, the dehydrogenation of DHQ derivatives (Scheme 12) has emerged as an easy and fast strategy to prepare QZs under different oxidant conditions (Table 11). Initially, QZs were obtained by dehydrogenation of DHQs by means of $\mathrm{ZnCl}_{2}$ in the presence of air, with $42 \%$ yield and in 10 h. ${ }^{202}$ A catalystfree reaction in an open flask in refluxing $\mathrm{EtOH}$ was completed in few hours. ${ }^{258}$ The oxidation of DHQs by the addition of 2,3dichloro-5,6-dicyano-1,4-benzoquinone also gave the corresponding oxidized derivatives with $83 \%$ yield. ${ }^{231}$ Various oxidizing agents were used for the dehydrogenation of DHQs to efficiently generate QZs, with 26-92\% yield. ${ }^{259-262}$ Metalcatalyzed dehydrogenation was also attempted, affording the oxidized derivatives in moderate to good yields (18-85\%) but in 16-24 h. ${ }^{263-265}$ Biocatalysis using laccase $/ N$-hydroxybenzotriazole gave QZs in $62-87 \%$ yield. ${ }^{266}$

\section{DHQ as a versatile fragment in drug design}

The purpose of drug discovery has always been the design and development of "magic bullets" targeting a single key biomolecule in a central pathway of a specific disease. This led to the dominant paradigm "one target, one drug", which might be inadequate to achieve a therapeutic effect for complex diseases. ${ }^{267,268}$ For this reason, the polypharmacology research and the design of multitarget compounds is considerably emerging, ${ }^{269,270}$ contributing to overcome some of the limitations of classical approach, in term of risks and costs. ${ }^{271} \mathrm{DHQ}$ is a versatile fragment that can be easily functionalized at different positions. The introduction of specific moieties in the DHQ nucleus leads to the ability to interact with multiple 

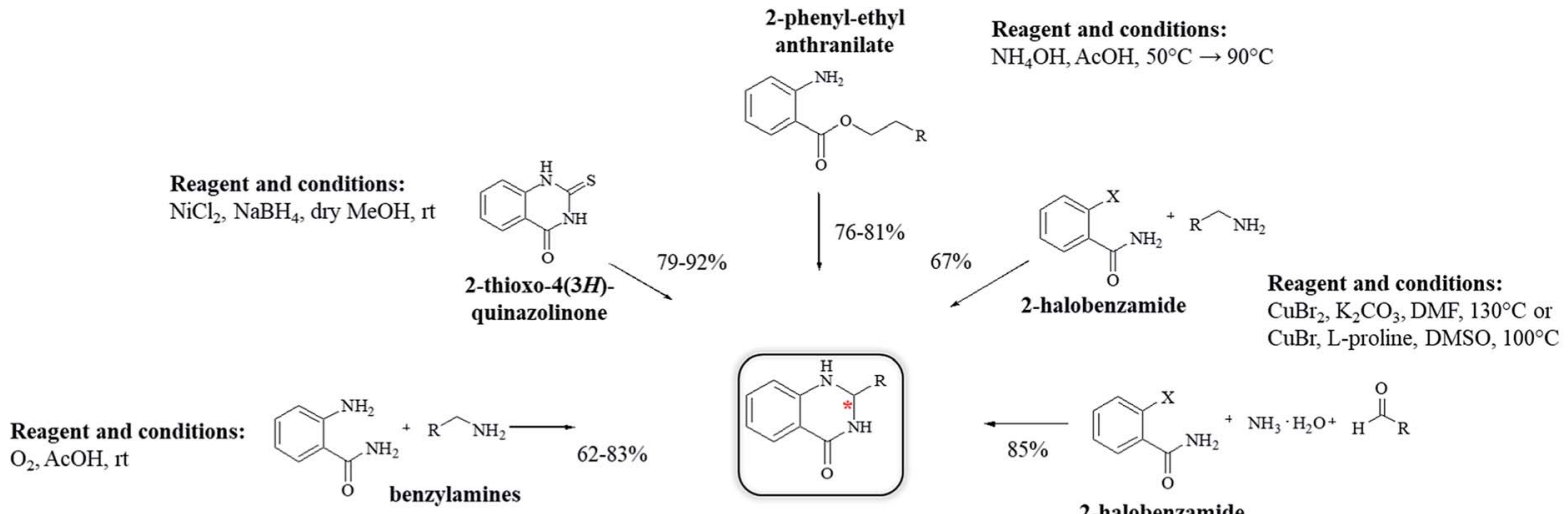

2-halobenzamide

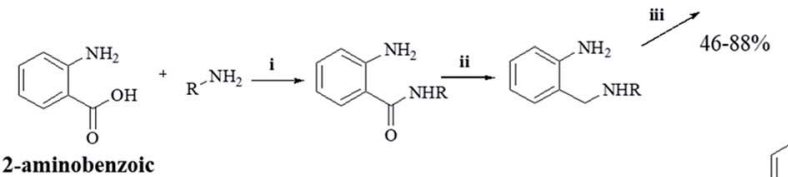
acid

Reagent and conditions: i: $\mathrm{SiCl}_{4}, \mathrm{Py}, \mathrm{rt}$ ii: SMEAH, Toluene, reflux iii: $\mathrm{COCl}_{2} \mathrm{Et}, \mathrm{Py}, \mathrm{it}$

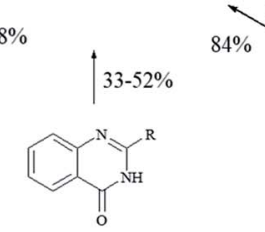

4(3H)-quinazolinone

Reagent and conditions $\mathrm{NaBH}_{4}$, diglyme, $85^{\circ} \mathrm{C}$ or $\mathrm{NaBH}_{4}, \mathrm{AcOH}, 50^{\circ} \mathrm{C}$ or rt

Scheme 10 Alternative synthetic strategies from diverse starting materials.

targets, ensuring diverse pharmacological properties that make it a privileged scaffold (Fig. 5).

\section{2-Aryl DHQ derivatives}

The anticancer activity of DHQ derivatives was one of the first to be discovered. In 1967, Yale et al. identified DHQs as a new class of inhibitors of cell proliferation of the Earle's L cells. In particular, 2-aryl derivatives showed significant in vitro activity with low median effective dose $\left(\mathrm{ED}_{50}\right)$ values of $0.1-6 \mu \mathrm{g} \mathrm{ml}{ }^{-1} .^{13}$ The antitumor activity of various 2-aryl DHQs against different cancer cell lines was then confirmed by several laboratories. ${ }^{26,36,38,109,272}$ Although many efforts to explain their cytotoxicity have been made, the target of the DHQ framework remains unknown. Almost three decades later, Hamel et al. used COMPARE algorithm to suggest that the antitumor effect of 2aryl DHQs resulted from interactions with tubulin. Some derivatives inhibited the polymerization of tubulin at low micromolar concentrations and the binding of radiolabeled colchicine to tubulin at higher doses. ${ }^{273}$ Furthermore, based on the crystal structure of $\alpha, \beta$-tubulin in complex with colchicine, through computational docking experiments and molecular dynamics, it was rationalized that $(S)$-DHQs may bind to tubulin better than the $(R)$-enantiomers, showing a better antitumor activity. ${ }^{3}$ In the same study, the accumulation of DHQs in the cytoplasm of MDA-MB-435 cells was observed through the inherent fluorescent properties of DHQs. ${ }^{3}$ In order to improve the antitumor effect of DHQs with antimitotic properties, a tumor-targeting liposomal delivery system that incorporates an anti-transferrin receptor single-chain antibody fragment was used, showing preferential targeting of tumor cells.. ${ }^{274} 2$ -
Quinolin-5-yl DHQ induced cytochrome $c$ mediated apoptosis and autophagy in human leukemia MOLT-4 cells as demonstrated by flow cytometry, microscopy, LC3 immunofluorescence, and western blot analysis. ${ }^{275}$ Other pathways have been suggested to clarify the antitumor activity of DHQ derivatives. DHQs bearing a phenyl substituent and piperidine/piperazine moiety on C5 and C7 respectively were identified as selective inhibitors of p38 MAP kinase. They efficiently repressed the production of TNF- $\alpha$ in monocyte, THP-1 cells and LPSstimulated whole blood ( $\mathrm{IC}_{50}$ values in the nanomolar range). These analogs had good clearance but low oral bioavailability in rats. However, the introduction of a bulky $t$-butyl substituent on the piperidine nitrogen significantly increased the oral exposure in rats. ${ }^{276}$ Other DHQ derivatives were discovered by a highthroughput screening as inhibitors of the Hedgehog pathway, involved in embryonic development and oncogenesis. The biochemical mechanism of action of these DHQs was the inhibition of the AAA+ ATPase motor cytoplasmic dynein that converts chemical energy into mechanical force and regulates many cellular processes, including ciliary trafficking, formation of mitotic spindle and organelle transport. These AAA+ ATPase inhibitors could be useful to study cellular processes that require microtubule motor. ${ }^{277}$ Different targets were proposed to cause the antitumor activity of 2-aryl DHQs. Among them are cathepsin $\mathrm{B}$ and $\mathrm{H}$, known to facilitate invasion, angiogenesis and metastasis through degradation of extracellular matrices and are associated with cancer progression.

Some 2-aryl DHQ derivatives were identified, through molecular docking studies, as reversible inhibitors of cathepsin $\mathrm{B}$ and $\mathrm{H}$ with effective inhibitory constant $\left(K_{i}\right)$ values in the 
Table 10 Catalysts for the enantioselective synthesis of DHQs

\begin{tabular}{|c|c|c|c|c|c|}
\hline Catalyst & Structure & Conditions & Time & $\%$ Yield & ee $\%$ \\
\hline TFA & & $\mathrm{CH}_{3} \mathrm{CN}, 45^{\circ} \mathrm{C}$ & $1.5 \mathrm{~h}$ & $34-85$ & 79-91 \\
\hline
\end{tabular}

$\mathrm{C}_{8}$-TRIP

9-Anthracenyl-TRIP

(R,R)-PhDAP

9-Anthracenyl-SPINOL<smiles>O=P(O)(O)Oc1c(-c2ccccc2)c(-c2cccc3ccccc23)c2ccccc2c1-c1c2ccccc2cc2ccccc12</smiles>

$\mathrm{CHCl}_{3}, \mathrm{rt}$ $\mathrm{CHCl}_{3}, \mathrm{rt}$

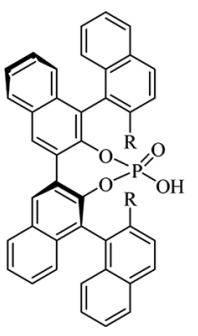

1,2-DFB, rt

$15 \mathrm{~h}$

99-100

80-86

242

$\mathrm{CHCl}_{3}, 3$ A $\mathrm{MS}, \mathrm{rt}$

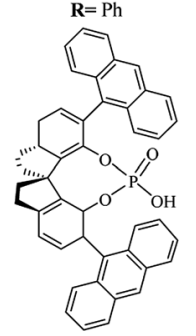<smiles>O=P(O)(Oc1ccccc1)Oc1c(-c2cc(C(F)(F)F)cc(C(F)(F)F)c2)cc2ccccc2c1-c1cc2ccc(COS(=O)(=O)c3ccccc3)cc2cc1-c1cc(C(F)(F)F)cc(C(F)(F)F)c1</smiles>

$\mathrm{CHCl}_{3},-15^{\circ} \mathrm{C}$

DCM, 4 ̊ MS, rt

DCM, 4 A MS, rt
24-48 h

73-99 30-94

90-99 241 10-96 244
Toluene, 5 A MS, $-45^{\circ} \mathrm{C} \quad 24 \mathrm{~h} \quad 67-94 \quad 26-98 \quad 240$

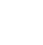

\section{(2)}

$24 \mathrm{~h}$

$88-9$

59-98 243

BINOL-derived phosphoric acid

$\operatorname{Sc}(\mathrm{OTf})_{3} /$ Pybox<smiles>C[C@]12Cc3ccccc3C[C@H]1OC(c1cccc(C3=N[C@@H]4c5ccccc5C[C@]4(C)O3)n1)=N2</smiles>

$6-48 \mathrm{~h}$

$80-94$

86-98

246

$\mathrm{Sc}(\mathrm{OTf})_{3} / \mathrm{L} 6$
81-94

87-98 Ref.

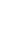

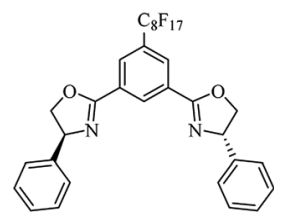


<smiles>NC(=O)c1ccccc1N</smiles>

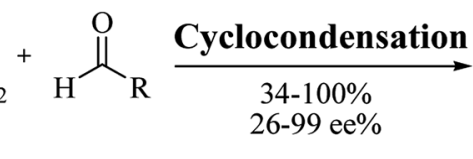<smiles>[R]C1NC(=O)c2ccccc2N1</smiles>

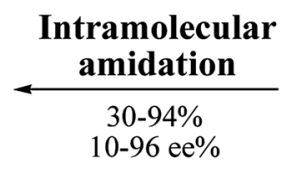<smiles>[R]C(=NC(=O)OCc1ccccc1)C(N)=O</smiles>

Scheme 11 Enantioselective synthesis of DHQs.

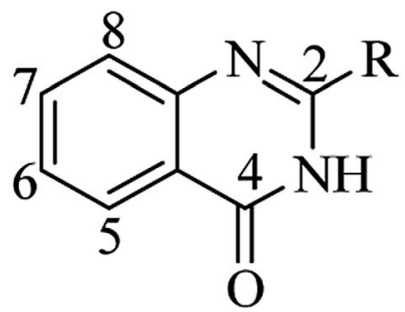

Fig. 4 Quinazolin-4(3H)-one framework.

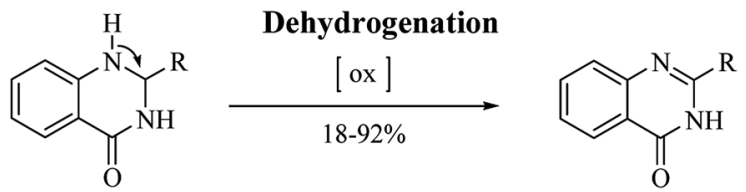

Scheme 12 Dehydrogenation of DHQs as intermediate in organic synthesis.

nanomolar range. ${ }^{278}$ Through virtual and in vitro screening, 2aryl DHQs were found to be potent tankyrase 2 inhibitors ( IC $_{50}$ ranging from low micromolar to nanomolar values). Crystal structures of tankyrase 2 with inhibitors showed that they interact with the nicotinamide-binding site of the catalytic domain of the enzyme. These compounds also inhibited Wnt/ $\beta$ catenin pathway in a cell-based assay. ${ }^{279}$ Development of hybrid compounds that incorporate two pharmacophores in a single molecule with improved potency is gaining momentum. A new class of hybrids was designed and synthesized from DHQ and 3,5-diaryl isoxazoline/isoxazoles, linked through alkane spacers, and their antitumor activity was evaluated. Derivatives with 3C chain spacers showed excellent potency against lung cancer, exhibiting nanomolar $\mathrm{IC}_{50}$ values. Flow cytometric analysis revealed G2/M cell cycle arrest, usually associated with the inhibition of tubulin polymerization. Furthermore, these compounds disrupt microtubules, inhibit cyclin B1, CDK1, and induce apoptosis in cancer cells. ${ }^{280} \mathrm{~N}$-indolylmethyl substituted spiroindoline-3,2'-DHQ were hypothesized as potential sirtuin inhibitors. Sirtuins, whose family consists of seven members (SIRT1-7), are important targets for cancer therapy, being upregulated in several types of cancer. In particular, SIRT1 has several substrates, including p53 and NF-kB, and its inhibition leads to the re-expression of silenced tumor suppressor genes and the subsequent decrease of cancer cell growth. These new DHQ derivatives were obtained through $\mathrm{Pd} / \mathrm{C}-\mathrm{Cu}-\mathrm{mediated}$ coupling cyclization and tested in vitro using a yeast homologue of mammalian SIRT1, Sir 2 protein, showing dosedependent inhibition. Molecular docking analysis showed that the benzene ring of the DHQ occupied the deep hydrophobic pocket of the protein, while the $\mathrm{NH}$ and the sulfonyl groups form $\mathrm{H}$-bonding interaction with select amino acid residues (Val412 and Gly415). ${ }^{281}$ Over half a century ago, DHQ derivatives bearing a sulfonamide moiety on $\mathrm{C} 7$ showed diuretic activity, causing natriuresis and chloruresis and a slight increase of potassium excretion after oral administration. ${ }^{282}$ Among them, fenquizone is a FDA-approved drug for the treatment of edema and hypertension..$^{283-286}$ The substitution of $\mathrm{C} 8$ with $\mathrm{N}$ in the benzene ring of DHQ and the introduction of

Table 11 Reaction conditions for the dehydrogenation of DHQs

\begin{tabular}{|c|c|c|c|c|}
\hline Catalyst & Conditions & Time & $\%$ Yield & Ref. \\
\hline $\mathrm{ZnCl}_{2}$ & $\mathrm{AcOH}$, air, reflux & $10 \mathrm{~h}$ & 42 & 202 \\
\hline Catalyst-free & EtOH, air, reflux & $3 \mathrm{~h}$ & 65 & 258 \\
\hline $\mathrm{MnO}_{2}$ & $\mathrm{DCM}, \mathrm{rt}$ & $2 \mathrm{~h}$ & $39-79$ & 221 \\
\hline $\mathrm{MnO}_{2}$ & $\mathrm{CHCl}_{3}, \mathrm{rt}$ & $5-20 \mathrm{~h}$ & $26-75$ & 259 \\
\hline $\mathrm{KMnO}_{4}$ & DMF, reflux & $2-3 \mathrm{~h}$ & $85-90$ & 191 \\
\hline $\mathrm{O}_{2}$ & $\mathrm{AcOH}, 150{ }^{\circ} \mathrm{C}$ & $24 \mathrm{~h}$ & $46-72$ & 239 \\
\hline $\mathrm{SO}_{2}$ & $\mathrm{DMF} / \mathrm{H}_{2} \mathrm{O}$, air or $\mathrm{N}_{2}, 90^{\circ} \mathrm{C}$ & $5 \mathrm{~h}$ & $65-92$ & 261 \\
\hline $\mathrm{K}_{2} \mathrm{~S}_{2} \mathrm{O}_{8}$ & $\mathrm{CH}_{3} \mathrm{CN}, 90^{\circ} \mathrm{C}$ & $3-16 \mathrm{~h}$ & $55-90$ & 262 \\
\hline $\mathrm{CuBr}$ & $\mathrm{K}_{2} \mathrm{CO}_{3}$, DMSO, air, $130^{\circ} \mathrm{C}$ & $24 \mathrm{~h}$ & $18-85$ & 263 \\
\hline $\mathrm{FeCl}_{3}$ & $\mathrm{~K}_{2} \mathrm{CO}_{3}$, toluene, $120^{\circ} \mathrm{C}$ & $16 \mathrm{~h}$ & $45-85$ & 264 \\
\hline $\mathrm{Ph}_{3} \mathrm{PAuNTf}_{2}$ & Toluene, $100{ }^{\circ} \mathrm{C}$ & $24 \mathrm{~h}$ & & 265 \\
\hline
\end{tabular}




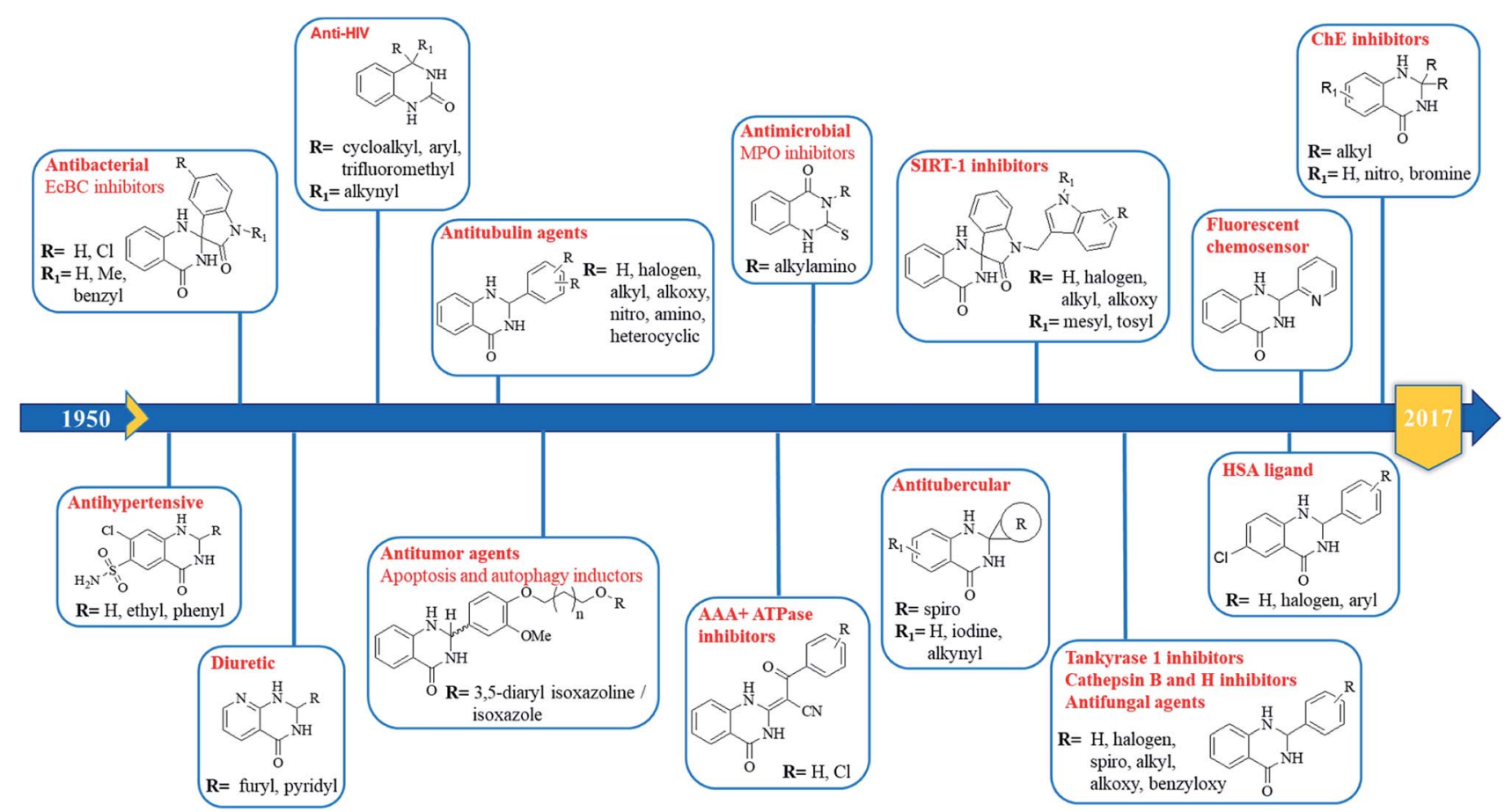

Fig. 5 Pharmacological activities of DHQ derivatives.

a pyridyl moiety on $\mathrm{C} 2$ led to 1,2-dihydro-2-(3-pyridyl)-3H-pyrido $[2,3-d]$ pyrimidin-4-one derivatives. They also showed diuretic activity. ${ }^{287}$ Some DHQ derivatives also show broad-spectrum antimicrobial properties. 2-(5-Nitro-2-thienyl) DHQs showed antibacterial activity against Hemophilus vaginalis and Escherichia coli strains, responsible for bacterial vaginitis, exhibiting low minimal inhibitory concentration (MIC, ranging from 0.4 to $\left.12.5 \mu \mathrm{g} \mathrm{ml}^{-1}\right) .{ }^{288}$ More recently, some spiro-oxindole DHQs have shown significant antibacterial activity against both Grampositive and Gram-negative bacterial strains, in particular $E$. coli. In order to explain the mechanism of this antibacterial activity, DHQs were docked on E. coli biotin carboxylase (EcBC) enzyme. EcBC is a known target of the fatty acid biosynthetic pathway since it catalyzes the ATP-dependent carboxylation of the vitamin biotin. Molecular docking results showed that the DHQ core fit in the hydrophobic enclosure formed by Ile437 and His236, and the different substituents form $\mathrm{H}$-bonds as well as hydrophobic interactions with specific amino acid residues. ${ }^{289}$

Tuberculosis, an infectious disease caused by Mycobacterium tuberculosis, is a worldwide leading cause of death. Multiple antibiotics are needed to treat tuberculosis over a long period of time, but the development of multiple drug-resistant tuberculosis limits complete recovery. Some spiro-DHQ derivatives were tested for their in vitro inhibitory activity against Mycobacterium tuberculosis $\mathrm{H} 37 \mathrm{Rv}$ chorismite mutase, a promising target for the identification of new antitubercular drugs. These derivatives showed a moderate inhibition at relatively high doses (30 $\mu \mathrm{M}) .^{290}$ 2-Aryl DHQs also show moderate to good antifungal activities, in particular against Candida albicans and Aspergillus niger. ${ }^{43}$ A class of 2-thioxo DHQ derivatives showed an excellent antimicrobial activity by inhibiting myeloperoxidase. This enzyme plays an important role in host defense and contributes to inflammation. They reversibly inhibited myeloperoxidase, exhibiting $\mathrm{IC}_{50}$ values in the nanomolar range. ${ }^{291}$ 4-Alkynyl-3,4dihydro-2 $(1 H)$-quinazolinones, bearing a second substituent at position 4, such as cycloalkyl, aryl and trifluoromethyl were identified as potent HIV-1 non-nucleoside reverse transcriptase inhibitors, inhibiting wild-type and various mutant forms of HIV-1. These compounds also showed a good oral bioavailability. ${ }^{292-294}$ 2-Aryl DHQ derivatives, with or without substituents on N1 and N3, were found to interact with human serum albumin (HSA), using fluorescence spectroscopy. The therapeutic effects of drugs depend on their absorption, distribution, metabolism and excretion, and can be influenced by the binding affinities of drugs with HSA. In particular, strong binding can reduce free drug concentrations in plasma whereas weak binding can decrease lifetime and/or distribution of drugs. Results of site marker competitive experiments revealed that DHQs spontaneously bind to HSA on site II, subdomain IIIA, though hydrophobic forces. Various substituents in the benzene ring of DHQ could increase the interactions with HSA, forming additional van der Waals forces and H-bonds. ${ }^{295-297}$ Transition metals, such as iron, zinc and copper, play important roles in the human body. Specifically, copper is a catalytic cofactor for a variety of metalloenzymes and physiological processes. Increased levels of copper in the body could be involved in the production of reactive oxygen species (ROS), causing imbalance in cellular functions and several diseases. For this reason, the development of fluorescent chemosensors for biologically active transition metal ions are becoming attractive. In this regard, 2-aryl DHQs were efficiently used as fluorescent probes to selectively detect $\mathrm{Cu}^{2+}$ ions. ${ }^{298}$ 
<smiles>[R][Y]1ccc2c(c1)N([X])C([R])N([Y])C2=O</smiles>

\begin{tabular}{|c|c|c|c|c|c|}
\hline $\mathrm{R}$ & $\mathrm{X}$ & $\mathrm{Y}$ & $\mathrm{R}_{1}$ & Activity/mechanism & Ref. \\
\hline Alkyl, cycloalkyl & Phenyl, benzyl & $\mathrm{H}$ & $\begin{array}{l}\mathrm{H} \text {, alkyl, alkoxy, amino, } \\
\text { nitro }\end{array}$ & Anti-inflammatory & 298 and 299 \\
\hline Dimethyl & $\begin{array}{l}\text { Alkyl, cycloalkyl, } \\
\text { aryl }\end{array}$ & $\mathrm{H}$ & Heterocycles & PKC $\theta$ inhibitors & 301 \\
\hline $\mathrm{H}$ & Phenyl & $\mathrm{H}$ & $\begin{array}{l}\text { Amide, alkylamino, } \\
\text { sulfonamine }\end{array}$ & p38 MAPK inhibitors & 302 \\
\hline $\begin{array}{l}\text { H, phenyl, furyl, } \\
\text { phenylamino }\end{array}$ & $\mathrm{H}$ & $\begin{array}{l}\text { Alkylamino, } \\
\text { cycloalkylamino, } \\
\text { hydroxy, alkoxy }\end{array}$ & $\mathrm{H}$ & Antibacterial & 311 and 312 \\
\hline Phenyl & $\mathrm{H}$ & Alkylamino & $\mathrm{H}$ & Antimalarial & 313 \\
\hline $\begin{array}{l}\text { Thienyl, furyl, } \\
\text { pyrrolidinyl }\end{array}$ & $\mathrm{H}$ & Phenyl & $\mathrm{H}$ & Antiviral & 314 and 315 \\
\hline $\begin{array}{l}\text { Thienyl, pyridinyl, } \\
\text { indolyl }\end{array}$ & $\mathrm{H}$ & Phenyl & $\mathrm{H}$ & $\begin{array}{l}\text { Antiprotozoal/shiga } \\
\text { toxin }\end{array}$ & 316 \\
\hline Phenyl & $\mathrm{H}$ & $\begin{array}{l}\text { Furan-2-ylmethyl, } \\
\text { benzyl }\end{array}$ & H, hydroxy, methoxy & TSHR inhibitors & 45 and 305 \\
\hline Alkyl & $\mathrm{H}$ & $\begin{array}{l}\text { Biphenyl with } o^{-} \\
\text {tetrazole }\end{array}$ & $\mathrm{H}$, alkoxy & $\begin{array}{l}\text { Angiotensin II receptor } \\
\text { antagonists }\end{array}$ & 234 \\
\hline Alky, spiro & $\mathrm{H}$ & Alkyl & Phenyl, benzyloxy & Antifungal/lysozyme & 317 \\
\hline Pyridinyl-1 $H$-pyrazolyl & $\mathrm{H}$ & Alkyl, cycloalkyl & $\mathrm{H}$, alkyl, halo & $\begin{array}{l}\text { Insecticidal/calcium } \\
\text { channels }\end{array}$ & 318 \\
\hline Alkyl, phenyl & $\mathrm{H}$ & Alkyl & $\mathrm{H}$, alkyl & $\begin{array}{l}\text { Anticonvulsant } / \mathrm{Na}^{+} / \\
\mathrm{Ca}^{2+} \text { exchanger } \\
\text { inhibitors }\end{array}$ & 230 and 319 \\
\hline $\mathrm{H}$ & $\mathrm{H}$ & Heterocycles & $\mathrm{H}$, heterocycles & CDK5 inhibitors & 320 \\
\hline $\mathrm{H}$ & $\mathrm{H}$ & Heterocycles & $\mathrm{H}$ & $\begin{array}{l}\mathrm{M}_{1} \text { and } \mathrm{M}_{4} \text { receptors } \\
\text { agonists }\end{array}$ & 321 \\
\hline Keto & $\mathrm{H}$ & 2-Oxoindolinyl & $\mathrm{H}$ & Antitumor & 322 \\
\hline $\mathrm{H}$ & $\mathrm{H}$ & Phenyl & Amino, phenyl & $\begin{array}{l}\text { Antitumor/p38 MAPK } \\
\text { inhibitors }\end{array}$ & 323 \\
\hline Keto, spiro & $\mathrm{H}$ & Alkyl, aryl & Methoxy, oxazolyl & IMPDH II inhibitors & 324 \\
\hline $\mathrm{H}$, methyl & $\begin{array}{l}\text { Acyl, alkyl, } \\
\text { phenyl }\end{array}$ & Aryl & $\mathrm{H}$ & $\begin{array}{l}\text { Analgesic and anti- } \\
\text { inflammatory }\end{array}$ & 300 and 326 \\
\hline $\mathrm{H}$ & Acyl & Alkyl, phenyl & $\mathrm{H}$ & $\begin{array}{l}\text { Choleretic and } \\
\text { antifibrillatory }\end{array}$ & 327 \\
\hline
\end{tabular}

A series of 2-disubstituted DHQ derivatives showed inhibitory activity against cholinesterases (ChE), involved in the lysis of choline-based esters that act as neurotransmitters. Acetylcholinesterase is present in chemical synapses and in red blood cell membranes, and butyrylcholinesterase is found in blood plasma. ChE inhibitors are the only effective therapeutic approach for the symptomatic treatment of Alzheimer's disease. These derivatives inhibited both enzymes ( $\mathrm{IC}_{50}$ values in micromolar range), better than or comparable to the standard drug galantamine. Molecular docking studies revealed that the benzene ring of DHQs can fits into the choline-binding site while the phenyl ring at position 2 is oriented towards the peripheral anionic site. The NH group of DHQs and Asp72 form an ion-dipole interaction, while substituents in the benzene ring are involved in $\mathrm{H}$-bonding interactions. ${ }^{16}$

\section{Mono- and di-substituted DHQ derivatives}

As a privileged scaffold, the DHQ nucleus is amenable to modification. The most common functionalization was the single introduction of different chemical groups on heterocyclic $\mathrm{N} 1$ and mainly on N3, and substitutions on both positions. The resulting mono- and di-substituted derivatives showed specific activities depending on the substituents (Table 12).

1-Substituted DHQs can be synthesized similarly to the unsubstituted derivatives, starting from anthranilic acid ${ }^{284}$ and isatoic anhydride, ${ }^{299,300}$ bearing substituents on the amino group and the heterocyclic $\mathrm{N}$ respectively, or 2-fluorobenzonitrile (Scheme 13). ${ }^{301}$ Most DHQ derivatives bearing aryl substituents on N1 showed good anti-inflammatory properties. ${ }^{298,299}$ Some 1-(2-phenylethyl) DHQs were found to inhibit IL- 


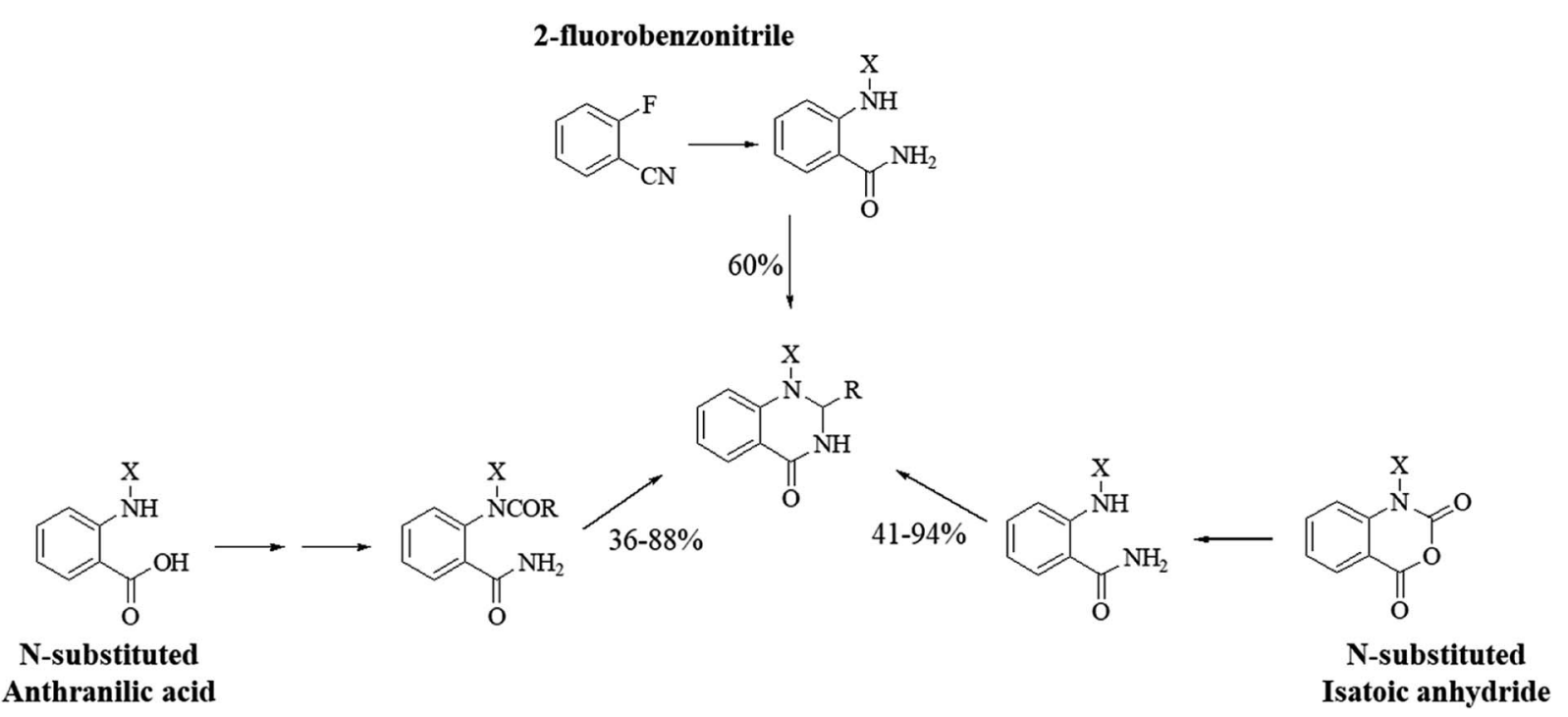

Scheme 13 Synthetic strategies for 1-substituted DHQ derivatives.

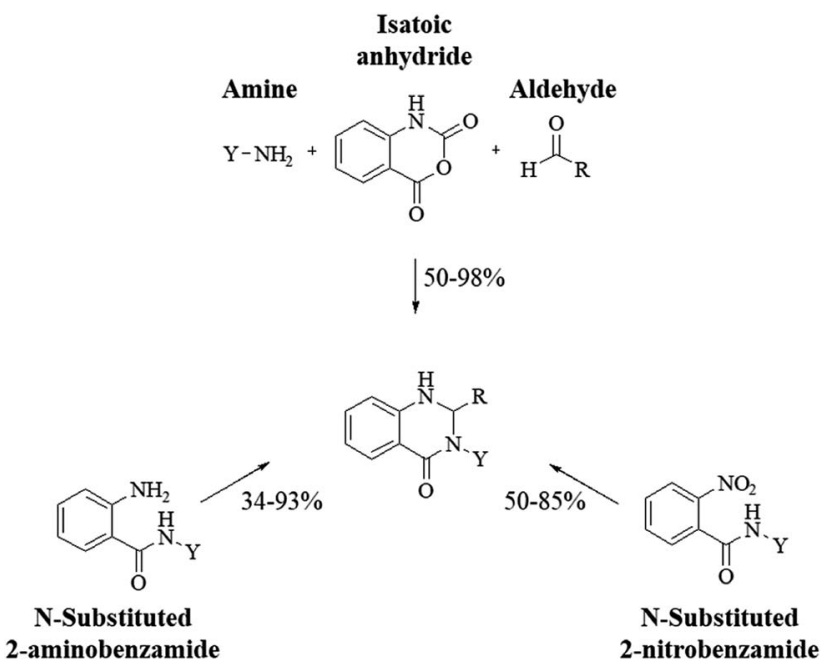

Scheme 14 Synthetic strategies for 3-substituted DHQ derivatives.

2 production through inhibition of the protein kinase $\mathrm{C}-\theta$ (PKC $\theta),{ }^{301}$ while 1-aryl-6-substituted DHQs inhibited p38 in vitro at nanomolar concentrations. ${ }^{302}$

More commonly, 3-substituted DHQs were synthesized by cyclocondensation of 2-aminobenzamides, ${ }^{303-305}$ or 2-nitrobenzamides, ${ }^{306}$ substituted on the amide groups, with different aldehydes. 3-substituted DHQs could be also obtained through the one-pot three-component reaction of isatoic anhydride with amines and aldehydes (Scheme 14). ${ }^{307-310}$ DHQ derivatives bearing cyclic amino substituents on N3 showed antibacterial activity, ${ }^{31,312}$ while 3-alkylamino DHQs exhibited antimalarial effects. $^{313}$ Different heterocycles like thienyl, furyl and pyrrolidinyl in position 2 or 3-phenyl DHQs were responsible for antiviral activity, ${ }^{\mathbf{3 4 , 3 1 5}}$ and for the protective effect against Shiga toxin. ${ }^{316}$ 3-(Furan-2-ylmethyl) derivatives were reported as thyroid-stimulating hormone receptor agonists. ${ }^{45,305} 3$-Biphenyl substituted DHQs with a tetrazole ring in the ortho position acted as angiotensin II receptor antagonists. ${ }^{234}$ 3-Alkyl substituted DHQs bind to lysozyme showing antifungal activity. ${ }^{317}$ Certain 3-alkyl and 3-cycloalkyl DHQ derivatives exhibit insecticidal properties by targeting calcium channels. ${ }^{318}$ On the other hand, 3-alkyl and 3-alkylamino substituted 3,4dihydro-2 $(1 H)$ quinazolinones show anticonvulsant activity ${ }^{230}$ and inhibited the $\mathrm{Na}^{+} / \mathrm{Ca}^{2+}$ exchanger. ${ }^{319}$ Other 3,4-dihydro$2(1 H)$ quinazolinones bearing heterocyclic substituents at position 3 showed neuroprotective and antipsychotic properties, inhibiting cyclin-dependent kinase 5 (CDK5), ${ }^{320}$ and targeting $\mathbf{M}_{1}$ and $\mathbf{M}_{4}$ muscarinic acetylcholine receptors, ${ }^{321}$ respectively. 3-(2-Oxoindolin-3-yl) DHQ derivatives showed antiproliferative activity against human tumor cell lines $\left(\mathrm{IC}_{50}\right.$ in the micromolar range). ${ }^{322}$ Other 3-aryl and 3-alkyl DHQs also showed antitumor properties, inhibiting p38 MAP kinase, ${ }^{323}$ and inosine $5^{\prime}$ monophospate dehydrogenase type II (IMPDH II). ${ }^{\mathbf{3 2 4}}$

The less studied 1,3-disubstituted DHQs could be obtained in two different ways: through the cyclization of $N$-substituted isatoic anhydride and substituted arylidene anilines, ${ }^{299}$ or the reaction of 3-substituted DHQ with chloride (Scheme 15). ${ }^{325}$ 1,3-<smiles></smiles>

Scheme 15 Synthetic strategies for 1,3-disubstituted DHQ derivatives. 
Disubstituted DHQ derivatives mostly showed anti-analgesic and inflammatory activities. ${ }^{300,326}$ 1-Acyl DHQs bearing alkyl and phenyl substituents on $\mathrm{N}$ showed choleretic and antifibrillatory activities. ${ }^{327}$

\section{Conclusions}

The importance of the DHQ nucleus has emerged due to its versatility as suitable substrate for functionalization and its remarkable bioactivities. Many procedures have been reported for the synthesis of DHQ derivatives as racemic mixture. Although the cyclocondensation of anthranilamide and an aldehyde and the one-pot three-component reaction of isatoic anhydride, ammonium acetate and an aldehyde represent the most common ways to obtain DHQ derivatives, several other methods have been suggested. Many approaches have been investigated, from classical to greener and more sustainable reaction conditions. Recently, enantioselective strategies have been attempted in order to obtain pure $(S)$-enantiomers. Furthermore, the DHQ scaffold is an important intermediate in organic chemistry and can easily be oxidized into QZ scaffold. On the other hand, various important bioactivities have been associated to the DHQ scaffold and reported in the literature. On this basis, the DHQ nucleus imposes itself as a privileged scaffold in drug design and an interesting fragment for drug discovery.

\section{Conflicts of interest}

There are no conflicts to declare.

\section{References}

1 K. Imtiaz, I. Aliya, A. Waqas and S. Aamer, Eur. J. Med. Chem., 2015, 90, 124-169.

2 P. D. Leeson and B. Springthorpe, Nat. Rev. Drug Discovery, 2007, 6, 881-890.

3 G. M. Chinigo, M. Paige, S. Grindrod, E. Hamel, S. Dakshanamurthy, M. Chruszcz, W. Minor and M. L. Brown, J. Med. Chem., 2008, 51, 4620-4631.

4 B. E. Evans, K. E. Rittle, M. G. Bock, R. M. DiPardo, R. M. Freidinger, W. L. Whitter, G. F. Lundell, D. F. Veber, P. S. Anderson, R. S. L. Chang, V. J. Lotti, D. J. Cerino, T. B. Chen, P. J. Kling, K. A. Kunkel, J. P. Springer and J. Hirshfield, J. Med. Chem., 1988, 31, 2235-2246.

5 D. A. Horton, G. T. Bourne and M. L. Smythe, Chem. Rev., 2003, 103, 893-930.

6 https:/www.drugbank.ca.

7 R. Williams, C. M. Niswender, Q. Luo, U. Le, P. J. Conn and C. W. Lindsley, Bioorg. Med. Chem. Lett., 2009, 19, 962-966.

8 Y. Kobayashi, Y. Nakano, K. Hoshikuma, Y. Yokoo and T. Kamiya, Planta Med., 2001, 67, 628-633.

9 A. N. Hughes, I. Rafi, M. J. Griffin, A. H. Calvert, D. R. Newell, J. A. Calvete, A. Johnston, N. Clendeninn and A. V. Boddy, Clin. Cancer Res., 1999, 5, 111-118.

10 R. V. Coombs, R. P. Danna, M. Denzer, G. E. Hardtmann, B. Huegi, G. Koletar, J. Koletar, H. Ott, E. Juckniewicz,
J. W. Perrine, E. I. Takesue and J. H. Trapold, J. Med. Chem., 1973, 16, 1237-1245.

11 S. Seyedmousavi, H. Rafati, M. Ilkit, A. Tolooe, M. T. Hedayati and P. Verweij, Methods and Protocols, 2016, 1508, 107-139.

12 M. Shahraki, S. M. Habibi-khorassani and Y. Narouei, Am.J. Chem. Appl., 2015, 2, 83-90.

13 H. L. Yale and M. Kalkstein, J. Med. Chem., 1967, 10, 334336.

14 G. Bonola and E. Sianesi, J. Med. Chem., 1970, 13, 329-332. 15 R. J. Ericsson and E. Reif, US pat.3651061, 1972.

16 M. Sarfraz, N. Sultana, U. Rashid, M. S. Akram, A. Sadiq and M. I. Tariq, Bioorg. Chem., 2017, 70, 237-244.

17 N. Saroja, E. Laxminarayana and K. R. S. Prasad, Indian J. Heterocycl. Chem., 2014, 24, 67-70.

18 S. D. Sharma and V. Kaur, Synthesis, 1989, 1989, 677-680.

19 M. Hour, L. Huang, S. Kuo, K. Bastow, Y. Nakanishi, E. Hamel and K. Lee, J. Med. Chem., 2000, 43, 4479-4487.

20 S. Kuo, M. Hour, L. Huang and K. Lee, US pat 6479499 B1, 2002.

21 J. J. Naleway, C. M. J. Fox, D. Robinhold, E. Terpetschnig, N. A. Olson and P. Haugland, Tetrahedron Lett., 1994, 35, 8569-8572.

22 V. B. Labade, P. V. Shinde and M. S. Shingare, Tetrahedron Lett., 2013, 54, 5778-5780.

23 A. G. Al-Sehemi, M. Pannipara and A. Kalam, Spectrochim. Acta, Part A, 2017, 171, 97-103.

24 X. Liu, D. Hu and H. Shen, Asian J. Chem., 2012, 24, 13651367.

25 M. Wang, J. Gao, Z. Song and L. Wang, Org. Prep. Proced. Int., 2012, 44, 159-163.

26 R. Navudu, G. R. Mannem, T. Margani, U. M. R. Vanga and H. B. Bollikolla, Asian J. Chem., 2016, 28, 1321-1324.

27 S. Esfandiari, M. T. Maghsoodlou, S. M. Habibi-Khorassani, S. Kiaee and J. Aboonajmi, Iranian Journal of Organic Chemistry, 2012, 4, 827-830.

28 M. J. Mphahlele, M. M. Maluleka and T. Khoza, Bull. Chem. Soc. Ethiop., 2014, 28, 81-90.

29 M. Desroses, M. Scobie and T. Helleday, New J. Chem., 2013, 37, 3595-3597.

30 X. Wang, K. Yang, J. Zhou and S. Tu, J. Comb. Chem., 2010, 12, 417-421.

31 X. Wang, K. Yang, M. Zhang and C. Yao, Synth. Commun., 2010, 40, 2633-2646.

32 Y. Nagasawa, Y. Matsusaki, T. Nobuta, N. Tada, T. Miura and A. Itoh, $R S C A d v ., 2015$, 5, 63952-63954.

33 F. Miklós, V. Hum and F. Fülöp, ARKIVOC, 2014, 2014, 2537.

34 D. M. Boghaei, M. M. Najafpour and V. Mckee, Acta Crystallogr., Sect. E: Struct. Rep. Online, 2009, E65, 0193.

35 M. Abdollahi-Alibeik and E. Shabani, Chin. Chem. Lett., 2011, 22, 1163-1166.

36 N. Ramesh, M. G. Rao, R. Valara, V. U. Rao and B. H. Babu, Med. Chem. Res., 2016, 25, 1945-1951.

37 Y. Luo, Y. Wu, Y. Wang, H. Sun, Z. Xie, W. Zhang and Z. Gao, RSC Adv., 2016, 6, 66074-66077. 
38 L. Rajaka, N. R. Penumati, K. Nagaiah, Y. Poornachandra and C. G. Kumar, Synth. Commun., 2015, 45, 1893-1901.

39 K. R. Gopinath, H. S. Shekar, K. J. Rajendraprasad, H. Nagabhushana and M. Krishnappa, WJPPS, 2016, 5, 1272-1279.

40 M. Sharma, S. Pandey, K. Chauhan, D. Sharma, B. Kumar and P. M. S. Chauhan, J. Org. Chem., 2012, 77, 929-937.

41 S. Kobayashi, M. Sugiura, H. Kitagawa and W. W. Lam, Chem. Rev., 2002, 102, 2227-2302.

42 J. X. Chen, H. Y. Wu and W. K. Su, Chin. Chem. Lett., 2007, 18, 536-538.

43 S. Vasudhevan and R. J. Karunakaran, Int. J. PharmTech Res., 2013, 5, 2844-2853.

44 P. Sivaguru, K. Parameswaran and A. Lalitha, Tetrahedron Lett., 2016, 57, 2549-2553.

45 E. E. Englund, S. Neumann, E. Eliseeva, J. G. McCoy, S. Titus, W. Zheng, N. Southall, P. Shin, W. Leister, C. J. Thomas, J. Inglese, C. P. Austin, M. C. Gershengorn and W. Huang, MedChemComm, 2011, 2, 1016-1020.

46 S. Wang, K. Yang and X. Wang, Chin. J. Org. Chem., 2011, 8, 1235-1239.

47 Y. Shang, L. Fan, X. Li and M. Liu, Chin. Chem. Lett., 2015, 26, 1355-1358.

48 S. Li, W. Jhang, T. Liou and D. Yang, Dyes Pigm., 2015, 114, 259-266.

49 A. Shaabani, A. Maleki and H. Mofakham, Synth. Commun., 2008, 38, 3751-3759.

50 M. Wang, J. J. Gao, Z. G. Song and L. Wang, Chem. Heterocycl. Compd., 2011, 47, 851-855.

51 R. Venkatesh, S. Kasaboina, H. K. Gaikwad, S. Janardhan, R. Bantu, L. Nagarapu, G. N. Sastry and S. K. Banerjee, Eur. J. Med. Chem., 2015, 96, 22-29.

52 R. Noel, J. Martinez, D. Buisson, L. Johannes, D. Gillet, J. Barbier and J. Cintrat, J. Med. Chem., 2013, 56, 3404-3413.

53 R. M. Christie and S. Moss, J. Chem. Soc., Perkin Trans. 1, 1985, 1, 2779-2783.

54 A. Ghorbani-Choghamarani, Z. Darvishnejad and M. Norouzi, Appl. Organomet. Chem., 2015, 29, 707-711.

55 P. Hanumanthu, S. K. V. Seshavatharam, C. V. Ratnam and N. V. S. Rao, Proc. Indian Acad. Sci., 1976, 84, 57-63.

56 P. R. Kumar and S. Reddy, Synth. Commun., 1992, 22, 24992508.

57 R. P. Staiger, C. L. Moyer and G. R. Pitcher, J. Chem. Eng. Data, 1963, 8, 454-456.

58 A. Dömling, Chem. Rev., 2006, 106, 17-86.

59 M. Narasimhulu and Y. R. Lee, Tetrahedron, 2011, 67, 96279634.

60 S. Khaksar and M. Gholami, Res. Chem. Intermed., 2015, 41, 3709-3718.

61 M. Baghbanzadeh, P. Salehi, M. Dabiri and G. Kozehgary, Synthesis, 2006, 2, 344-348.

62 B. Chen, J. Li and G. Chen, Ultrason. Sonochem., 2015, 23, 59-65.

63 A. Davoodnia, M. Khashi and N. Tavakoli-Hoseini, Chin. J. Catal., 2014, 35, 1054-1058.

64 Z. Song, L. Liu, Y. Wang and X. Sun, Res. Chem. Intermed., 2012, 38, 1091-1099.
65 Z. Song, X. Wan and S. Zhao, Indian J. Chem. Technol., 2012, 19, 118-123.

66 M. Wang, T. T. Zhang, Y. Liang and J. J. Gao, Monatsh. Chem., 2012, 143, 835-839.

67 R. Ghorbani-Vaghei, A. Shahriari, Y. Maghbooli and J. Mahmoudi, Res. Chem. Intermed., 2017, 43, 983-993.

68 L. Zeng and C. Cai, J. Heterocycl. Chem., 2010, 47, 10351039.

69 S. Rostamizadeh, A. M. Amani, R. Aryan, H. R. Ghaieni and N. Shadjou, Synth. Commun., 2008, 38, 3567-3576.

70 M. Wang, T. T. Zhang, Y. Liang and J. J. Gao, Chin. Chem. Lett., 2011, 22, 1423-1426.

71 J. Chen, D. Wu, F. He, M. Liu, H. Wu, J. Ding and W. Su, Tetrahedron Lett., 2008, 49, 3814-3818.

72 X. Zhu, S. R. Kang, L. Xia, J. Lee, N. Basavegowda and Y. R. Lee, Mol. Diversity, 2015, 19, 67-75.

73 L. Sancineto, N. Iraci, S. Massari, V. Attanasio, G. Corazza, M. L. Barreca, S. Sabatini, G. Manfroni, N. R. Avanzi, V. Cecchetti, C. Pannecouque, A. Marcello and O. Tabarrini, ChemMedChem, 2013, 1941-1953.

74 J. Szejtli, Chem. Rev., 1998, 98, 1743-1753.

75 S. V. Bhosale and S. V. Bhosale, Mini-Rev. Org. Chem., 2007, 4, 231-242.

76 K. Ramesh, K. Karnakar, G. Satish, K. H. V. Reddy and Y. V. D. Nageswar, Tetrahedron Lett., 2012, 53, 6095-6099.

77 K. Ramesh, K. Karnakar, G. Satish, B. S. P. Anil Kumar and Y. V. D. Nageswar, Tetrahedron Lett., 2012, 53, 6936-6939.

78 D. R. Patil, P. G. Ingole, K. Singh and D. S. Dalal, J. Inclusion Phenom. Macrocyclic Chem., 2013, 76, 327-332.

79 J. Wu, X. Du, J. Ma, Y. Zhang, O. Shi, L. Luo, B. Song, S. Yang and D. Hu, Green Chem., 2014, 16, 3210-3217.

80 M. T. Maghsoodlou, N. Khorshidi, M. R. Mousavi, N. Hazeri and S. M. Habibi-Khorassani, Res. Chem. Intermed., 2015, 41, 7497-7508.

81 H. R. Shaterian and F. Rigi, Res. Chem. Intermed., 2015, 41, 721-738.

82 M. Dabiri, P. Salehi, S. Otokesh, M. Baghbanzadeh, G. Kozehgary and A. A. Mohammadi, Tetrahedron Lett., 2005, 46, 6123-6126.

83 A. Ghorbani-Choghamarani and T. Taghipour, Lett. Org. Chem., 2011, 8, 470-476.

84 Y. Chen, W. Shan, M. Lei and L. Hu, Tetrahedron Lett., 2012, 53, 5923-5925.

85 M. P. Surpur, P. R. Singh, S. B. Patil and S. D. Samant, Synth. Commun., 2007, 37, 1965-1970.

86 S. Ikegami and H. Hamamoto, Chem. Rev., 2009, 109, 583593.

87 M. Moreno-Man and R. Pleixats, Acc. Chem. Res., 2003, 36, 638-643.

88 Z. Zhang, H. Lü, S. Yang and J. Gao, J. Comb. Chem., 2010, 12, 643-646.

89 M. Z. Kassaee, S. Rostamizadeh, N. Shadjou, E. Motamedi and M. Esmaeelzadeh, J. Heterocycl. Chem., 2010, 47, 1421-1424.

90 J. Zhang, D. Ren, Y. Ma, W. Wang and H. Wu, Tetrahedron, 2014, 70, 5274-5282. 
91 S. Santra, M. Rahman, A. Roy, A. Majee and A. Hajra, Catal. Commun., 2014, 49, 52-57.

92 M. Hajjami, A. Ghorbani-Choghamarani, Z. Yousofvand and M. Norouzi, J. Chem. Sci., 2015, 127, 1221-1228.

93 N. Ravazi and B. Akhlaghinia, New J. Chem., 2016, 40, 447457.

94 J. Lu and P. H. Toy, Chem. Rev., 2009, 109, 815-838.

95 A. Gharib, B. R. Hashemipour, M. Jahangir, M. Roshani and R. Safaee, Org. Chem. Int., 2013, 2013, 848237.

96 A. Gharib, L. Vojdanifard, N. Noroozi Pesyan, B. R. Hashemi Pou Khorasani, M. Jahangir and M. Roshani, Bulg. Chem. Commun., 2014, 46, 667-679.

97 G. Majid, A. Kobre, M. Hamed and S. Hamid Reza, Chin. J. Chem., 2011, 29, 1617-1623.

98 A. Maleki, M. Rabbani and S. Shahrokh, Appl. Organomet. Chem., 2015, 29, 809-814.

99 R. Mekala, M. V. Madhubabu, G. Dhanunjaya, S. Regati, K. B. Chandrasekhar and J. Sarva, Synth. Commun., 2017, 47, 121-130.

100 P. Salehi, M. Dabiri, M. A. Zolfigol and M. Baghbanzedeh, Synlett, 2005, 7, 1155-1157.

101 M. Dabiri, P. Salehi, M. Baghbanzadeh, M. A. Zolfigol, M. Agheb and S. Heydari, Catal. Commun., 2008, 9, 785788.

102 K. Niknam, M. Mohammadizadeh and S. Mirzaee, Chin. J. Chem., 2011, 29, 1417-1422.

103 K. Niknam, N. Jafarpour and E. Niknam, Chin. Chem. Lett., 2011, 22, 69-72.

104 A. Ghorbani-Choghamarani and P. Zamani, J. Iran. Chem. Soc., 2012, 9, 607-613.

105 S. Rostamizadeh, A. M. Amani, G. Mahdavinia, H. Sepehrian and S. Ebrahimi, Synthesis, 2010, 8, 13561360.

106 A. Shokrolahi, A. Zali, M. A. Zare and K. Esmaeilpour, Iran. J. Catal., 2012, 2, 91-94.

107 P. Sivaguru, K. Parameswaran, M. Kiruthiga, P. Vadivel and A. Lalitha, J. Iran. Chem. Soc., 2015, 12, 95-100.

108 H. R. Shaterian and F. Rigi, Res. Chem. Intermed., 2014, 40, 2983-2999.

109 H. R. Shaterian, A. R. Oveisi and M. Honarmand, Synth. Commun., 2010, 40, 1231-1242.

110 H. R. Shaterian, N. Fahimi and K. Aziz, Res. Chem. Intermed., 2014, 40, 1879-1898.

111 S. Li, Q. Zhang and Y. Peng, Monatsh. Chem., 2015, 146, 1859-1864.

112 A. Saffar-Teluri and S. Bolouk, Monatsh. Chem., 2010, 141, 1113-1115.

113 P. Salehi, Synth. Commun., 2006, 36, 2287-2292.

114 S. M. Roopan, F. N. Khan, J. S. Jin and R. S. Kumar, Res. Chem. Intermed., 2011, 37, 919-927.

115 F. Serp, M. Corrias and P. Kalck, Appl. Catal., A, 2003, 253, 337-358.

116 J. Safari and S. Gandomi-Ravandi, J. Mol. Catal. A: Chem., 2013, 371, 135-140.

117 J. Safari and S. Gandomi-Ravandi, C. R. Chim., 2013, 16, 1158-1164.
118 J. Safari and S. Gandomi-Ravandi, J. Mol. Struct., 2014, 1072, 173-178.

119 J. Safari and S. Gandomi-Ravandi, J. Saudi Chem. Soc., 2017, 21, S415-S424.

120 L. Wang, L. Hu, J. Shao, J. Yu and L. Zhang, J. Fluorine Chem., 2008, 129, 1139-1145.

121 R. Sharma, A. K. Pandey and P. M. S. Chauhan, Synlett, 2012, 23, 2209-2214.

122 M. Wang, T. T. Zhang, J. J. Gao and Y. Liang, Chem. Heterocycl. Compd., 2012, 6, 897-902.

123 Á. Magyar and Z. Kell, Catal. Lett., 2016, 146, 1153-1162.

124 P. T. Anastas and J. C. Warner, Green Chemistry: Theory and Practice, Oxford University Press, Oxford, 1998.

125 D. L. Hjeresen, D. L. Schett and J. M. Boese, J. Chem. Educ., 2000, 77, 1543-1547.

126 R. Mestres, Environ. Sci. Pollut. Res., 2005, 12, 128-132.

127 J. L. Tucker, Org. Process Res. Dev., 2006, 10, 315-319.

128 P. V. N. S. Murthy, D. Rambabu, G. Rama Krishna, C. Malla Reddy, K. R. S. Prasad, M. V. Basaveswara Rao and M. Pal, Tetrahedron Lett., 2012, 53, 863-867.

129 M. Wang, J. Gao, Z. Song and L. Wang, J. Heterocycl. Chem., 2012, 49, 1250-1253.

130 A. Rostami and A. Tavakoli, Chin. Chem. Lett., 2011, 22, 1317-1320.

131 A. D. Roy, K. Jayalakshmi, S. Dasgupta, R. Roy and B. Mukhopadhyay, Magn. Reson. Chem., 2008, 46, 11191126.

132 H. R. Shaterian and A. R. Oveisi, Chin. J. Chem., 2009, 27, 2418-2422.

133 M. Singh and N. Raghav, Bioorg. Chem., 2015, 59, 12-22.

134 S. B. Bharate, N. Muppararu, S. Manda, J. B. Bharate, R. Mudududdla, R. R. Yadav and R. A. Vishwakarma, ARKIVOC, 2012, 2012, 308-318.

135 M. Ghashang, Orient. J. Chem., 2012, 28, 1213-1218.

136 S. D. Dindulkar, J. Oh, V. M. Arole and Y. T. Jeong, C. $R$. Chimie, 2014, 17, 971-979.

137 A. Ghorbani-Choghamarani and B. Tahmasbi, New J. Chem., 2016, 40, 1205-1212.

138 M. Hajjami, A. Ghirbani-Choghamarani, R. Ghafouri-Nejad and B. Tahmasbi, New J. Chem., 2016, 40, 3066-3074.

139 B. A. Dar, A. K. Sahu, P. Patidar, Y. Parial, P. Sharma, M. Sharma and B. Singh, Am. J. Chem., 2012, 2, 248-254.

140 B. A. Dar, A. K. Sahu, P. Patidar, P. R. Sharma, N. Mupparapu, D. Vyas, S. Maity, M. Sharma and B. Singh, J. Ind. Eng. Chem., 2013, 19, 407-412.

141 B. V. Subba Reddy, A. Venkateswarlu, C. Madan and A. Vinu, Tetrahedron Lett., 2011, 52, 1891-1894.

142 A. V. Dhanunjaya, B. P. Vykunteswararao, T. Bhaskarkumar, N. R. Jogdand, D. Kalita, J. K. D. Lilakar, V. Siddaiah, P. D. Sanasi and A. Raghunadh, Tetrahedron Lett., 2015, 56, 4714-4717.

143 A. Ghorbani-Choghamarani and G. Azadi, RSC Adv., 2015, 5, 9752-9758.

144 A. Rostami, B. Tahmasbi, H. Gholami and H. Taymorian, Chin. Chem. Lett., 2013, 24, 211-214.

145 M. Ghashang, S. S. Mansoor and K. Aswin, Res. Chem. Intermed., 2015, 41, 3447-3460. 
146 M. Abdollahi-Alibeik and E. Shabani, J. Iran. Chem. Soc., 2014, 11, 351-359.

147 H. R. Safaei, M. Shekouhy, S. Khademi, V. Rahmanian and M. Safaei, J. Ind. Eng. Chem., 2014, 20, 3019-3024.

148 M. Rahman, I. Ling, N. Abdullah, R. Hashim and A. Hajra, $R S C A d v .$, 2015, 5, 7755-7760.

149 X. Zong, Y. Zhao, W. Luo, X. H. Yu, J. K. Wang and Y. Pan, Chin. Chem. Lett., 2010, 21, 778-781.

150 M. Tajbakhsh, R. Hosseinzadeh, P. Rezaee and M. Tajbakhsh, Chin. J. Catal., 2014, 35, 58-65.

$151 \mathrm{H}$. Alinezhadi, E. Soleymani and M. Zare, Res. Chem. Intermed., 2017, 43, 457-466.

152 J. Wang, Y. Zong, R. Fu, Y. Niu, G. Yue, Z. Quan, X. Wang and Y. Pan, Ultrason. Sonochem., 2014, 21, 29-34.

153 S. Zhang, Z. Xie, L. Liu, M. Liang and Z. Le, Chin. Chem. Lett., 2017, 28, 101-104.

154 A. Maleki and S. Shahrokh, 1st International Electronic Conference on Materials, 26 May-10 June 2014.

155 N. Kausar, I. Roy, D. Chattopadhyay and A. R. Das, RSC Adv., 2016, 6, 22320-22330.

156 J. Safari and S. Gandomi-Ravandi, J. Mol. Catal. A: Chem., 2014, 390, 1-6.

157 J. Safari and S. Gandomi-Ravandi, RSC Adv., 2014, 4, 1165411660.

158 A. Ghorbani-Choghamarani and M. Norouzi, J. Mol. Catal. A: Chem., 2014, 395, 172-179.

159 F. Havasi, A. Ghorbani-Choghamarani and F. Nikpour, Microporous Mesoporous Mater., 2016, 224, 26-35.

160 B. B. F. Mirjalili, A. Bamoniri and S. Azad, J. Iran. Chem. Soc., 2017, 14, 47-55.

161 P. Sivaguru, K. Parameswaran and A. Lalitha, Tetrahedron Lett., 2016, 57, 2549-2553.

162 W. Wei, C. C. K. Keh, C. Li and R. S. Varma, Clean Technol. Environ. Policy, 2005, 7, 62-69.

163 A. K. Chakraborti and S. R. Roy, J. Am. Chem. Soc., 2009, 131, 6902-6903.

164 A. Patil, M. Barge, G. Rashinkar and R. Salunkhe, Mol. Diversity, 2015, 19, 435-445.

165 S. K. Ghosh and R. Nagarajan, RSC Adv., 2015, 6, 2737827387.

166 M. Dabiri, P. Salehi and M. Baghbanzadeh, Monatsh. Chem., 2007, 138, 1191-1194.

167 M. Zhang, Y. Liu and X. Wang, Chin. J. Org. Chem., 2014, 34, 1682-1686.

168 M. Li and C. Feng, Acta Crystallogr., Sect. E: Struct. Rep. Online, 2009, E65, o2145.

169 J. Chen, W. Su, M. Liu and C. Jin, Green Chem., 2007, 9, 972975.

170 N. B. Darvatkar, S. V. Bhilare, A. R. Deorukhkar, D. G. Raut and M. M. Salunkhe, Green Chem. Lett. Rev., 2010, 3, 301306.

171 H. Alinezhad, M. Tajbakhsh and N. Ghobadi, Res. Rev. Mater. Sci. Chem., 2014, 3, 123-135.

172 M. Nikpassand, L. Zare Fekri, K. F. Sina, S. Z. Abed and O. Marvi, Russ. J. Gen. Chem., 2015, 85, 1959-1964.

173 S. Nagarajan, T. M. Shaikh and E. Kandasamy, New J. Chem., 2015, 39, 9693-9699.
174 G. Yassaghi, A. Davoodnia, S. Allameh, A. Zare-Bidaki and N. Tavakoli-Hoseini, Bull. Korean Chem. Soc., 2012, 33, 2724-2730.

175 F. S. Toosi and M. Khakzadi, Res. Chem. Intermed., 2015, 41, 311-317.

176 A. Davoodnia, S. Allameh, A. R. Fakhari and N. TavakoliHoseini, Chin. Chem. Lett., 2010, 21, 550-553.

177 M. A. B. Fard, A. Mobinikhaledi and M. Hamidinasab, Synth. React. Inorg. Met.-Org. Chem., 2014, 44, 567-571.

178 O. Obaiah, N. N. Kebbahalli, R. M. Goravanahalli, P. S. Chottanahalli, R. S. Kanchugarakoppal and M. Kempegowda, Eur. J. Chem., 2014, 5, 671-675.

179 H. R. Safaei, M. Shekouhy, V. Shafiee and M. Davoodi, J. Mol. Liq., 2013, 180, 139-144.

180 Z. Karimi-Jaberi and L. Zarei, S. Afr. J. Chem., 2012, 65, 3638.

181 Q. Ding, J. Zhang, J. Chen, M. Liu, J. Ding and H. Wu, J. Heterocycl. Chem., 2012, 49, 375-380.

182 V. B. Ningdale, U. N. Chaudhary and K. A. Shaikh, Arch. Appl. Sci. Res., 2013, 5, 82-87.

183 S. Zhaleh, N. Hazeri and M. T. Maghsoodlou, Res. Chem. Intermed., 2016, 42, 6381-6390.

184 D. Maitraie, G. Venkat Reddy, V. V. V. N. S. Rama Rao, S. Ravi Kanth, P. Shanthan Rao and B. Narsaiah, J. Fluorine Chem., 2002, 118, 73-79.

185 O. A. Maloshitskaya, J. Sinkkonen, V. V. Alekseyev, K. N. Zelenin and K. Pihlaja, Tetrahedron, 2005, 61, 72947303.

186 R. Z. Qiao, B. L. Xu and Y. W. Wang, Chin. Chem. Lett., 2007, 18, 656-658.

187 Y. Zheng, M. Bian, X. Deng, S. Wang and Z. Quan, Arch. Pharm. Chem. Life Sci., 2013, 346, 119-126.

188 P. Yerram, R. Chowrasia, S. Seeka and S. J. Tangenda, Eur. J. Chem., 2013, 4, 462-466.

189 R. Ramesh, N. Nagasundaram, D. Meignasundar, P. Vadivel and A. Lalitha, Res. Chem. Intermed., 2017, 43, 1767-1782.

190 Z. Xie, S. Zhang, G. Jiang, D. Sun and Z. Le, Green Chem. Lett. Rev., 2015, 8, 95-98.

191 M. Tímea, F. Miklós, L. Lázár and F. Fülöp, ARKIVOC, 2016, 2016, 247-258.

192 M. Wang, T. T. Zhang and Z. G. Song, Chin. Chem. Lett., 2011, 22, 427-430.

193 Z. Karimi-Jaberi and R. Arjmandi, Monatsh. Chem., 2011, 142, 631-635.

194 S. Khaksar and S. M. Talesh, C. R. Chimie, 2012, 15, 779783.

195 K. R. Rao, R. Mekala, A. Raghnadh, S. B. Meruva, S. P. Kumar, D. Kalita, E. Laxminarayana, B. Prasad and M. Pal, RSC Adv., 2015, 5, 61575-61579.

196 M. Hajjami, F. Bakhti and E. Ghiasbeygi, Croat. Chem. Acta, 2015, 88, 197-205.

197 A. Olyaei, F. Rahbarian and M. Sadeghpour, Chem. Heterocycl. Compd., 2015, 51, 899-902.

198 P. P. Naidu, A. Raghunadh, K. R. Rao, R. Mekala, J. M. Babu, B. R. Rao, V. Siddaiah and M. Pal, Synth. Commun., 2014, 44, 1475-1482. 
199 L. Gao, H. Ji, L. Rong, D. Tang, Y. Zha, Y. Shi and S. Tu, J. Heterocycl. Chem., 2011, 48, 957-960.

200 A. D. Gupta, S. Samanta and A. K. Mallik, Org. Prep. Proced. Int., 2015, 47, 356-360.

201 V. Polshettiwar and R. S. Varma, Pure Appl. Chem., 2008, 80, 777-790.

202 H. M. Hügel, Molecules, 2009, 14, 4936-4972.

203 F. Li, Y. Feng, Q. Meng, W. Li, Z. Li, Q. Wang and F. Tao, ARKIVOC, 2007, 2007, 40-50.

204 K. Kumari, D. S. Raghuvanshi and K. N. Singh, Indian J. Chem., 2012, 51B, 860-865.

205 R. S. Varma, Green Chem. Lett. Rev., 2007, 1, 37-45.

206 D. Rambabu, S. K. Kumar, B. Y. Sreenivas, S. Sandra, A. Kandale, P. Misra, M. V. B. Rao and M. Pal, Tetrahedron Lett., 2013, 54, 495-501.

207 J. A. Moore, G. J. Sutherland, R. Sowerby, E. G. Kelly, S. Palermo and W. Webster, J. Org. Chem., 1969, 34, 887892.

208 M. Soural, P. Funk, L. Kvapil, P. Hradil, J. Hlaváč and V. Bertolasi, ARKIVOC, 2010, 2010, 255-265.

209 M. Zhang, K. Yang and X. Wang, Acta Crystallogr., Sect. E: Struct. Rep. Online, 2010, E66, 01069.

210 A. J. A. Watson, A. C. Maxwell and J. M. J. William, Org. Biomol. Chem., 2012, 10, 240-243.

211 K. H. Narasimhamurthy, S. Chandrappa, K. S. Sharath, K. B. Harsha, H. Ananda and K. S. Rangappa, RSC Adv., 2014, 4, 34479-34486.

212 A. E. O. Lalami, S. Boukhris, N. Habbadi, N. B. Larb and A. Souizi, J. Maroc. Chim. Heterocycl., 2002, 1, 37-43.

213 N. T. Patil, R. D. Kavthe, V. S. Raut, V. S. Shinde and B. Sridhar, J. Org. Chem., 2010, 75, 1277-1280.

214 N. T. Patil, P. G. V. V. Lakshmi and V. Singh, Eur. J. Org. Chem., 2010, 4719-4731.

215 J. Tang, J. Li, L. Zhang, S. Ma, D. Shi, Q. Zhang, L. Yang, X. Wang, X. Liu and C. Liu, J. Heterocycl. Chem., 2012, 49, 533-542.

216 J. Tang, D. Shi, L. Zhang, Q. Zhang and J. Li, Synth. Commun., 2010, 40, 632-641.

217 L. Zhang, X. Yang, D. Shi and J. Chen, Acta Crystallogr., Sect. E: Struct. Rep. Online, 2008, E64, 0450.

218 P. N. Borase, P. B. Thale and G. S. Shankarling, RSC Adv., 2016, 6, 63078-63083.

219 X. Wy, S. Oschatz, A. Block, A. Spannenberg and P. Langer, Org. Biomol. Chem., 2014, 12, 1865-1870.

220 H. Chai, J. Li, L. Yang, M. Liu, D. Yang, Q. Zhang and D. Shi, Chin. J. Chem., 2014, 32, 865-870.

221 C. Balakumar, P. Lamba, D. P. Kishore, B. L. Narayana, K. V. Eao, K. Rajwinder, A. R. Rao, B. Shireesha and B. Narsajah, Eur. J. Med. Chem., 2010, 45, 4904-4913.

222 F. Tamaddon and F. Pouramini, Synlett, 2014, 25, 11271131.

223 D. Shi, L. Rong, J. Wang, Q. Zhuang, X. Wang and H. Hu, Tetrahedron Lett., 2003, 44, 3199-3201.

224 D. Shi, J. Wang, L. Rong, Q. Zhuang, S. Tu and H. Hu, J. Chem. Res., 2003, S, 671-673.

225 R. A. Bunce and B. Nammalwar, J. Heterocycl. Chem., 2011, 48, 991-997.
226 M. Wang, G. Dou and D. Shi, J. Comb. Chem., 2010, 12, 582586.

227 G. Cai, X. Xu, Z. Li, W. P. Weber and P. Lu, J. Heterocycl. Chem., 2002, 39, 1271-1272.

228 W. Su and B. Yang, Aust. J. Chem., 2002, 55, 695-697.

229 W. Su and B. Yang, J. Chem. Res., 2002, S, 604-605.

230 M. J. Kornet, J. Heterocycl. Chem., 1992, 29, 103-105.

231 N. Ho, R. S. Harapanhalli, B. A. Dahman, K. Chen, K. Wang, S. J. Adelstein and A. L. Kassis, Bioconjugate Chem., 2002, 13, 357-364.

232 H. Asakwa and M. Matano, Chem. Pharm. Bull., 1979, 27, 1287-1298.

233 Z. Xu, Y. Zhang, H. Fu, H. Zhong, K. Hong and W. Zhu, Bioorg. Med. Chem. Lett., 2011, 21, 4005-4007.

234 J. I. Levin, P. S. Chan, T. Bailey, A. S. Katocs and A. M. Venkatesan, The synthesis of 2,3-dihydro-4(1H)quinazolinone angiotensin II receptor antagonists, Bioorg. Med. Chem. Lett., 1994, 4, 1141-1146.

235 S. Guo, Y. Li, L. Tao, W. Zhang and X. Fan, RSC Adv., 2014, 4, 59289-59296.

236 B. Hu, L. Wang, J. Xiang, L. Yang and Y. Tang, Chin. Chem. Lett., 2015, 26, 369-372.

237 J. M. Khurana and G. Kukreja, J. Heterocycl. Chem., 2003, 40, 677-679.

238 P. Hradil, L. Kvapil, J. Hlaváč, T. Weidlich, A. Lyčka and K. Lemr, J. Heterocycl. Chem., 2000, 37, 831-837.

239 T. B. Nguyen, L. Ermolenko and A. Al-Mourabit, Green Chem., 2013, 15, 2713-2717.

240 X. Cheng, S. Vellalath, R. Goddard and B. List, J. Am. Chem. Soc., 2008, 130, 15786-15787.

241 M. Rueping, A. P. Antonchick, E. Sugiono and K. Grenader, Angew. Chem., Int. Ed., 2009, 48, 908-910.

242 T. Honjo, R. J. Phipps, V. Rauniyar and D. Toste, Angew. Chem., Int. Ed., 2012, 51, 9684-9688.

243 D. Huang, X. Li, F. Xu, L. Li and X. Lin, ACS Catal., 2013, 3, 2244-2247.

244 D. Cheng, Y. Tian and S. Tian, Adv. Synth. Catal., 2012, 354, 995-999.

245 B. Zhang, L. Shi and R. Guo, Catal. Lett., 2015, 145, 17181723.

246 M. Prakash and V. Kesavan, Org. Lett., 2012, 14, 1896-1899. 247 T. Deng, H. Wang and C. Cai, J. Fluorine Chem., 2015, 169, 72-77.

248 J. I. Levin, A. M. Venkatesan, P. S. Chan, J. S. Baker, G. Francisco, T. Bailey, G. Vice, A. Katocs, F. Lai and J. Coupet, Bioorg. Med. Chem. Lett., 1994, 4, 1135-1140.

249 Y. Kurogi, Y. Inoue, K. Tsutsumi, S. Nakamura, K. Nagao, H. Yoshitsugu and Y. Tsuda, J. Med. Chem., 1996, 39, 1433-1437.

250 V. J. Ram, Farhanullah, B. K. Tripathi and A. K. Srivastava, Bioorg. Med. Chem., 2003, 11, 2439-2444.

251 A. R. Maarouf, E. R. El-Bendary and F. E. Goda, Arch. Pharm. Pharm. Med. Chem., 2004, 337, 527-532.

252 S. M. Mosaad, M. K. Mohsen, M. M. K. Emad, A. Nageh, I. A. E. Sherein and F. A. Marwa, Eur. J. Med. Chem., 2010, 45, 3311-3319. 
253 M. N. Noolvi, H. M. Patel, V. Bhardwaj and A. Chauhan, Eur. J. Med. Chem., 2011, 46, 2327-2346.

254 Z. Xu, Y. Zhang, H. Fu, H. Zhong, K. Hong and W. Zhu, Bioorg. Med. Chem. Lett., 2011, 21, 4005-4007.

255 S. B. Mhaske and N. P. Argade, Tetrahedron, 2006, 62, 97879826.

256 U. A. Kshirsagar, Org. Biomol. Chem., 2015, 13, 9336-9352.

257 T. Panneer Selvam and P. Vijayaraj Kumar, Res. Pharm., 2015, 1, 1-21.

258 R. Pater, J. Heterocycl. Chem., 1971, 8, 699-702.

259 Y. Peng, Y. Zeng, G. Oiu, L. Cai and V. W. Pike, J. Heterocycl. Chem., 2010, 47, 1240-1245.

260 M. Bakavoli, O. Sabzevari and M. Rahimizadeh, Chin. Chem. Lett., 2007, 18, 1466-1468.

261 A. Romero, J. Salazar and S. E. López, Synthesis, 2013, 45, 2043-2050.

262 J. K. Laha, K. S. S. Tummalapalli, A. Nair and N. Patel, J. Org. Chem., 2015, 80, 11351-11359.

263 B. Hu, L. Wang, L. Yang, J. Xiang and Y. Tang, Eur. J. Org. Chem., 2015, 4504-4509.

264 M. Kumar, Richa, S. Sharma, V. Bhatt and N. Kumar, Adv. Synth. Catal., 2015, 357, 2862-2868.

265 L. Wang, B. Hu, J. Xiang, J. Cui, X. Hao, T. Liang and Y. Tang, Tetrahedron, 2014, 70, 8588-8591.

266 M. Heidary, M. Khoobi, S. Ghasemi, Z. Habibi and M. A. Faramarzi, Adv. Synth. Catal., 2014, 356, 1789-1794.

267 M. L. Bolognesi, Curr. Med. Chem., 2013, 20, 1639-1645.

268 M. L. Bolognesi and A. Cavalli, ChemMedChem, 2016, 11, 1190-1192.

269 R. Morphy, C. Kay and Z. Rankovic, Drug Discovery Today, 2004, 9, 641-651.

270 J. L. Mendina-Franco, M. A. Giulianotti, G. S. Welmarker and R. A. Houghten, Drug Discovery Today, 2013, 18, 495501.

271 R. Morphy and Z. Rankovic, J. Med. Chem., 2005, 48, 65236543.

272 N. M. Abdel Gawad, H. H. Georgey, R. M. Youssef and N. A. El-Sayed, Eur. J. Med. Chem., 2010, 45, 6058-6067.

273 E. Hamel, C. M. Lin, J. Plowman, H. Wang, K. Lee and K. D. Paull, Biochem. Pharmacol., 1996, 51, 53-59.

274 S. H. Hwang, A. Rait, K. F. Pirollo, Q. Zhou, V. M. Yenugonda, G. M. Chinigo, M. L. Brown and E. H. Chang, Mol. Cancer Ther., 2008, 7, 559-568.

275 S. Kumar, S. K. Guru, A. S. Pathania, N. Mupparapu, A. Kumar, F. Malik, S. B. Bharate, Q. N. Ahmed, R. A. Vishwakarma and S. Bhushan, Toxicol. Rep., 2014, 1, 1013-1025.

276 J. E. Stelmach, L. Liu, S. B. Patel, J. V. Pivnichny, G. Scapin, S. Singh, C. E. C. A. Hop, Z. Wang, J. R. Strauss, P. M. Cameron, E. A. Nichols, S. J. O'Keefe, E. A. O'Neil, D. M. Schmatz, C. D. Schmartz, C. M. Thompson, D. M. Zaller and J. B. Doherty, Bioorg. Med. Chem. Lett., 2003, 13, 277-280.

277 A. J. Firestone, J. S. Weinger, M. Maldonado, K. Barlan, L. D. Langston, M. O'Donnell, V. I. Gelfand, T. M. Kapoor and J. K. Chen, Nature, 2012, 484, 125-129.

278 M. Singh and N. Raghav, Bioorg. Chem., 2015, 59, 12-22.
279 J. Nkizinkiko, B. V. S. S. Kumar, V. U. Jeankumar, T. Haikarainen, J. Koivunen, C. Madhuri, P. Yogeeswari, H. Venkannagari, E. Obaji, T. Pihlajaniemi, D. Sriram and L. Lehtiö, Bioorg. Med. Chem., 2015, 23, 4139-4149.

280 A. Kamal, E. V. Bharathi, J. S. Reddy, M. J. Ramaiah, D. Dastagiri, M. K. Reddy, A. Viswanath, T. L. Reddy, T. B. Shaik, S. N. C. V. L. Pushpavalli and M. P. Bhadra, Eur. J. Med. Chem., 2011, 46, 691-703.

281 D. Rambabu, G. Raja, B. Y. Sreenivas, G. P. K. Seerapu, K. L. Kumar, G. S. Deora, D. Haldar, M. V. B. Rao and M. Pal, Bioorg. Med. Chem. Lett., 2013, 1351-1357.

282 E. Cohen, B. Klarberg and J. R. Vaughan, Organic Chemical Research Section, Lederle Laboratories Division, American Cyanamid Company, Pearl Rever, New York, 1959, vol. 81, pp. 5508-5509.

283 C. Ferrando, J. M. Foy, F. W. Pratt and I. R. Purvis, J. Pharm. Pharmacol., 1981, 33, 219-222.

284 A. Marzo, G. Quadro and E. Treffner, J. Chromatogr. B: Biomed. Sci. Appl., 1983, 272, 95-102.

285 A. Cupisti, F. Ciardella, E. Morelli, L. Dani, S. Lupetti, S. Luchi, M. Meola and G. Barsotti, Contrib. Nephrol., 1987, 58, 184-186.

286 F. V. Costa, C. Borghi, S. Boschi, A. Mussi and E. Ambrosini, J. Clin. Pharmacol., 1990, 30, 254-261.

287 H. A. Parish and R. D. Gilliom, J. Med. Chem., 1982, 25, 98102.

288 R. J. Alaimo and H. E. Russell, J. Med. Chem., 1972, 15, 335336.

289 J. Zhang, J. Zhao, L. Wang, J. Liu, D. Ren and Y. Ma, Tetrahedron, 2016, 72, 936-943.

290 D. Rambabu, S. K. Kumar, B. Y. Sreenivas, S. Sandra, A. Kandale, P. Misra, M. V. B. Rao and M. Pal, Tetrahedron Lett., 2013, 54, 495-501.

291 Y. Li, T. Ganesh, B. A. Diebold, Y. Zhu, J. W. McCoy, S. M. E. Smith, A. Sun and D. Lambeth, ACS Med. Chem. Lett., 2015, 6, 1047-1052.

292 T. J. Tucker, T. A. Lyle, C. M. Wiscount, S. F. Britcher, S. D. Young, W. M. Sanders, W. C. Lumma, M. E. Goldman, J. A. O'Brien, R. G. Ball, C. F. Homnick, W. A. Schleif, E. A. Emini, J. R. Huff and P. S. Anderson, J. Med. Chem., 1994, 37, 2437-2444.

293 J. W. Corbett, S. S. Ko, J. D. Rodgers, S. Jeffrey, L. T. Bacheler, R. M. Klabe, S. Diamond, C. Lai, S. R. Rabel, J. A. Saye, S. P. Adams, G. L. Trainor, P. S. Anderson and S. K. Erickson-Viitanen, Antimicrob. Agents Chemother., 1999, 43, 2893-2897.

294 J. W. Corbett, S. S. Ko, J. D. Rodgers, L. A. Gearhart, N. A. Magnus, L. T. Bacheler, S. Diamond, S. Jeffrey, R. M. Klabe, B. C. Cordova, S. Garber, K. Logue, G. L. Trainor, P. S. Anderson and S. K. Erickson-Viitanen, J. Med. Chem., 2000, 43, 2019-2030.

295 F. Liu, Y. Wang, L. Wang, J. Ou, M. Wang and S. Liu, Molecules, 2012, 17, 2000-2014.

296 Y. Wang, M. Zhu, F. Liu, X. Wu, D. Pan, J. Liu, S. Fan, Z. Wang, J. Tang, R. Na, Q. X. Li, R. Hua and S. Liu, Molecules, 2016, 21, 1373. 
297 Y. Wang, M. Zhu, J. Liu, R. Na, F. Liu, X. Wu, S. Fan, Z. Wang, D. Pan, J. Tang, Q. X. Li, R. Hua and S. Liu, Appl. Sci., 2017, 7, 200.

298 P. N. Borase, P. B. Thale and G. S. Shankarling, Dyes Pigm., 2016, 134, 276-284.

299 K. Ozaki, Y. Yamada, T. Oine, T. Ishizuka and Y. Iwasawat, J. Med. Chem., 1985, 28, 568-576.

300 Y. S. Sadanandam, K. R. M. Reddy and A. B. Rao, Eur. J. Med. Chem., 1987, 22, 169-173.

301 O. I. El-Sabbagh, S. M. Ibrahim, M. M. Baraka and H. Kothayer, Arch. Pharm. Chem. Life Sci., 2010, 343, 274281.

302 T. Katoh, T. Takai, T. Yukawa, T. Tsukamoto, E. Watanabe, H. Mototani, T. Arita, H. Hayashi, H. Nakagawa, M. G. Klein, H. Zou, H. Sang, G. Snell and Y. Nakada, Bioorg. Med. Chem., 2016, 24, 2466-2475.

303 A. Schlapbach, R. Heng and F. Di Padova, Bioorg. Med. Chem. Lett., 2004, 14, 357-360.

304 H. L. Yale, J. Heterocycl. Chem., 1977, 14, 1357-1359.

305 S. Neumann, W. Huang, E. Eliseeva, S. Titus, C. J. Thomas and M. C. Gershengorn, Endocrinology, 2010, 151, 34543459.

306 X. Zhu, S. R. Kang, L. Xia, J. Lee, N. Basavegowda and Y. R. Lee, Mol. Diversity, 2015, 19, 67-75.

307 C. L. Yoo, J. C. Fettinger and M. J. Kurth, J. Org. Chem., 2005, 70, 6941-6943.

308 L. Wang, L. Hu, J. Shao, J. Yu and L. Zhang, J. Fluorine Chem., 2008, 129, 1139-1145.

309 J. M. Khurana and S. Kumar, Green Chem. Lett. Rev., 2011, 4, 321-325.

310 A. Bharathi, S. M. Roopan, A. Kajbafvala, R. D. Padmaja, M. S. Darsana and G. N. Kumari, Chin. Chem. Lett., 2014, 25, 324-326.

311 A. Takács, A. Fodor, J. Németh and Z. Hell, Synth. Commun., 2014, 44, 2269-2275.

312 M. J. Namkung and T. L. Fletcher, J. Med. Chem., 1970, 13, 329-332.

313 A. A. Mohammadi, H. Rohi and A. A. Soorki, J. Heterocycl. Chem., 2013, 50, 1129-1133.

314 E. R. Derbyshire, J. Min, W. A. Guiguemde, J. A. Clark, M. C. Connelly, A. D. Magalhães, R. K. Guy and J. Clardy, Antimicrob. Agents Chemother., 2014, 58, 1516-1522.
315 C. D. S. Nelson, D. W. Carney, A. Derdowsky, A. Lipovsky, G. V. Gee, B. O'Hara, P. Williard, D. DiMaio, J. K. Sello and W. J. Atwood, mBio, 2013, 4, e00729.

316 D. W. Carney, C. D. Nelson, B. D. Ferris, J. P. Stevens, A. Lipovsky, T. Kazakov, D. DiMaio, W. J. Atwood and J. K. Sello, Bioorg. Med. Chem., 2014, 22, 4836-4847.

317 R. Noel, N. Gupta, V. Pons, A. Goudet, M. D. Garcia-Castillo, A. Michau, J. Martinez, D. Buisson, L. Johannes, D. Gillet, J. Barbier and J. Cintrat, J. Med. Chem., 2013, 56, 3404-3413.

318 K. Hemalatha, G. Mdhumitha, L. Ravi, V. G. Khanna, N. A. Al-Dhabi and M. V. Arasu, J. Photochem. Photobiol., $B, 2016,161,71-79$.

319 Y. Zhou, Q. Feng, F. Di, Q. Liu, D. Wang, Y. Chen, L. Xiong, H. Song, Y. Li and Z. Li, Bioorg. Med. Chem., 2013, 21, 49684975.

320 H. Hasegawa, M. Muraoka, K. Matsui and A. Kojima, Bioorg. Med. Chem. Lett., 2003, 13, 3471-3475.

321 R. M. Rzasa, M. R. Kaller, G. Liu, E. Magal, T. T. Nguyen, T. D. Osslund, D. Powers, V. J. Santora, V. N. Viswanadhan, H. Wang, X. Xiong, W. Zhong and M. H. Norman, Bioorg. Med. Chem., 2007, 15, 6574-6595.

322 Y. Uruno, Y. Konishi, A. Suwa, K. Takai, K. Tojo, T. Nakako, M. Sakai, T. Enomoto, H. Matsuda, A. Kitamura and T. Sumiyoshi, Bioorg. Med. Chem., 2015, 25, 5357-5361.

323 Y. Wang, X. Tang, Z. Shao, J. Ren, D. Liu, P. Proksch and W. Lin, J. Antibiot., 2014, 67, 395-399.

324 J. A. Hunt, F. Kallashi, R. D. Ruzek, P. J. Sinclair, I. Ita, S. X. McCormicl, J. V. Pivnichny, C. E. C. A. Hop, S. Kumar, Z. Wang, S. J. O'Keefe, E. A. O'Neill, G. Porter, J. E. Thompson, A. Woods, D. M. Zaller and J. B. Doherty, Bioorg. Med. Chem. Lett., 2003, 13, 467-470.

325 H. L. Birch, G. M. Buckely, N. Davies, H. J. Dyke, E. J. Frost, P. J. Glibert, D. R. Hannah, A. F. Haughan, M. J. Madigan, T. Morgan, W. R. Pitt, A. J. Ratcliffe, N. C. Ray, M. D. Richard, A. Sharpe, A. J. Taylor, J. M. Whitworth and S. C. Williams, Bioorg. Med. Chem. Lett., 2005, 15, 5335-5339.

326 K. Okumura, T. Oine, Y. Yamada, G. Hayashi and M. Nakama, J. Med. Chem., 1968, 11, 348-352.

327 G. Bonola, P. Da Re, M. J. Magistretti, E. Massarani and I. Setnikar, J. Med. Chem., 1968, 11, 1136-1139. 